Discussion Papers in Economics

\title{
Fiscal Policy in an Emerging Market Business Cycle Model
}

\author{
Chetan Ghate, Pawan Gopalakrishnan, Suchismita Tarafdar
}

December 2014

Discussion Paper 14-11

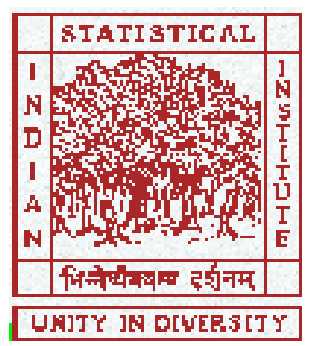

Indian Statistical Institute, Delhi

Economics and Planning Unit

7, S. J. S. Sansanwal Marg, New Delhi 110016, India 


\title{
Fiscal Policy in an Emerging Market Business Cycle Model*
}

\author{
${\text { Chetan } \text { Ghate }^{\dagger} \quad \text { Pawan Gopalakrishnan }}^{\ddagger} \quad$ Suchismita Tarafdar ${ }^{\S}$
}

December 8, 2014

\begin{abstract}
Emerging market economy business cycles are typically characterized by high consumption and output volatility, strongly counter-cyclical current accounts, and countercyclical real interest rates. Evidence from the wider EME and less developed economy business cycle experience suggests however that real interest rates can also be procyclical. We reconcile the pro-cyclicality of real interest rates with the above facts by embedding fiscal policy into a standard emerging market business cycle model. We show that fiscal policy makes real interest rates a-cyclical or pro-cyclical. We use the model to replicate qualitatively some of the key features of the Indian business cycle.
\end{abstract}

Keywords : Emerging Market Business Cycles, Fiscal Policy in a Small Open Economy, Indian Business Cycle, Interest Rate Shocks, Macroeconomic Stabilization

JEL Codes :E32; F32; F41; H2

${ }^{*}$ We thank Ken Kletzer, Chetan Subramanian, Elena Del Rey Canteli, and participants from the 2013 Singapore Economic Review Conference, the 2nd Delhi Macroeconomics Workshop (2013), the 2013 IMR Doctoral Conference (IIM Bangalore), the 9th Annual Growth and Development Conference (ISI Delhi), the 2013 Delhi School of Economics - Winter School, the 7th Economic Theory and Policy Conference (NIPFP, 2014), 2014 CSSS-CEDES workshop on Asymmetric Demography and Global Financial Governance (Kolkata), the 13th Journées Louis-André Gérard-Varet (Aix-en-Provence, 2014), and the 2014 Asian Meetings of the Econometric Society (Taipei). Chetan Ghate acknowledges hospitality from ICRIER (New Delhi) during 2012-2013 where part of this project was completed.

${ }^{\dagger}$ Corresponding Author: Economics and Planning Unit, Indian Statistical Institute, New Delhi - 110016, India. Tel: 91-11-4149-3938. Fax: 91-11-4149-3981. E-mail: cghate@isid.ac.in.

${ }_{\ddagger}^{\ddagger}$ Economics and Planning Unit, Indian Statistical Institute, New Delhi - 110016, India. Tel: 91-1127568306. Fax: 91-11-4149-3981. E-mail: pawan9r@isid.ac.in.

${ }^{\S}$ Department of Economics, School of Humanities and Social Science, Shiv Nadar University, Uttar Pradesh - 203207, India. Tel: 91-120-2663801. E-mail: suchismita.tarafdar@snu.edu.in. 


\section{Introduction}

Building dynamic stochastic general equilibrium (DSGE) models of emerging market economies (EMEs) has become an important area of research in macroeconomics. A recent empirical literature has identified key stylized facts in emerging market economy business cycles to see how these differ from the main features of advanced economy (AE) business cycles (see Agénor et al. (2000), Rand and Tarp (2002), Neumeyer and Perri (2005), Loayza et al. (2007), Male (2010), and Ghate et al. (2013)). The key stylized facts that these papers have identified are as follows. First, output in EMEs tends to be more volatile than output in advanced economies. ${ }^{1}$ Second, EMEs have counter-cyclical real interest rates. In AEs, real interest rates are typically a-cyclical or at the most mildly pro-cyclical. Third, consumption is pro-cyclical and more volatile than output in EMEs; in AEs, consumption is pro-cyclical but is less volatile than output. Fourth, net exports are much more counter-cyclical with respect to output in EMEs in comparison to the AEs.

This research has motivated new theoretical models to understand the propagation and amplification of shocks in EME business cycles. One branch of the literature builds upon the seminal work of Neumeyer and Perri (2005). ${ }^{2}$ These authors build a small open economy (SOE) real business cycle (RBC) model with interest rate shocks and working capital constraints. ${ }^{3}$ A higher interest rate implies that a firm's borrowing costs to meet its working capital constraint increases. This leads to a decline in the labor demanded by firms, and since this is a full employment model, a reduction in labor demand leads to a reduction in output. This channel makes real interest rates counter-cyclical. A crucial feature of this model is that households have GHH preferences (see Greenwood et al. (1988)). GHH preferences shut off the income effect, making labor supply invariant to the income effects associated with a positive interest rate shock (see Li (2011)). Consumption drops instantaneously and falls more than output due to the inter-temporal substitution effect from a rise in real interest rates. At the same time private investments also fall since the demand for private capital falls because of higher interest rates. As a result, net exports (defined as the savings-investment

\footnotetext{
${ }^{1}$ Male also (2010) estimates output to be on average twice as volatile in EMEs in comparison to AEs. Rand and Tarp (2002) on the contrary state that output is no more than 20\% more volatile in EMEs compared to AEs.

${ }^{2}$ Recently, Tiryaki (2012) estimates Neumeyer and Perri's (2005) model to replicate Turkey's business cycle properties.

${ }^{3}$ More specifically, in their model, firms face a working capital constraint, i.e., firms have to pay a fraction of the wage bill before actual production takes place. In order to finance this working capital constraint, firms issue corporate bonds to agents in international capital markets at a market determined interest rate on bonds. The interest rate has two different components - an international interest rate component and a country spread component driven by a shock to the country spread risk with the latter varying according to an individual country's sovereign risk.
} 
gap) displays counter-cyclicality with respect to output.

Another branch of theoretical models of EME business cycles builds on the seminal work of Aguiar and Gopinath (2007). These authors explain the key stylized facts of EME business cycles discussed above by allowing for both permanent trend shocks and transitory changes in productivity. Trend shocks affect both current income and future income. They justify this assumption by noting that emerging markets are characterized by a large number of policy regime shifts, which can be viewed as shocks to the trend productivity growth rate. Using the permanent income hypothesis as the identification mechanism, a shock to trend productivity implies a boost to both current output and also future output. Since a shock to the trend productivity increases permanent income, consumption increases more than income. This reduces savings, and generates a counter-cyclical current account deficit.

One aspect that is missing in the above theoretical literature is that there is no explicit role for fiscal policy. This is puzzling since fiscal policy plays an important role in macroeconomic stabilization in many developing countries and EMEs. ${ }^{4}$ For instance, Male (2010) finds that government expenditures tend to be significantly more volatile than output in EMEs and more volatile than government expenditures in AEs. She also reports that there is no robust stylized observation on the correlation between real government expenditure and output. ${ }^{5}$ In other evidence (see Talvi and Vegh (2005)), government expenditures have tended to be more pro-cyclical in EMEs than in AEs although there are countries where government expenditures are counter-cyclical. ${ }^{6}$ Our takeaway from this literature is that in some EMEs, government expenditures are counter-cyclical with respect to output and in others it is procyclical.

Another aspect that has typically not received sufficient attention is the role of fiscal policy for macroeconomic stabilization when an economy is hit with an interest rate shock. For instance, Male (2010) finds that a typical feature of these EMEs is that both government expenditures and real interest rates are more volatile than output. The contemporaneous

\footnotetext{
${ }^{4}$ Fiscal policy can serve as a stabilizing instrument if government expenditures are counter-cyclical along with pro-cyclicality of government revenues. One explanation for pro-cyclical government expenditure in EMEs is that governments often face political pressures or temptations to avoid budgetary surpluses during boom-time thereby constraining themselves from lowering expenditures or raising taxes. During recessions, governments in EMEs are forced to reduce spending because of lack of access to credit (see Talvi and Vegh $(2005))$. In the post great financial crisis period, there is also a renewed interest in fiscal policy in small open economies.

${ }^{5}$ Agénor et al. (2000) state that government expenditures tend to be more counter-cyclical in AEs as compared to EMEs.

${ }^{6}$ This is at odds with a volumnious literature that has found that fiscal policies are pre-dominantly procyclical in EMEs (Talvi and Vegh (2005), Cuadra el al. (2010)). Over the last decade, however, several EMEs have "graduated" from having pro-cyclical fiscal policy to having counter-cyclical fiscal policy. This "graduation" has been attributed to improvements in institutional quality (see Frankel et al. (2013)).
} 
correlation of the government expenditure and the real interest rate with respect to output however, is positive or negative. ${ }^{7}$ This is in contrast to advanced economies where real interest rates are observed to be a-cyclical or mildly pro-cyclical (see Agénor et al. (2000), Neumeyer and Perri (2005), and Male (2010)). In Table 1, we summarize the estimates of the relative standard deviation and contemporaneous correlations of government expenditures $(G)$ and real interest rates $(R)$ for 12 EMEs from Male (2010). ${ }^{8}$ In countries for which data is available, five countries have counter-cyclical real interest rates, while six have pro-cyclical interest rates. Further, while government expenditure is counter-cyclical in five countries, it is pro-cyclical in four.

Table 1 : Real interest rates and government expenditures in EMEs from Male (2010)

\begin{tabular}{cccccc}
\hline \hline Country & Sample & $\frac{\sigma(G)}{\sigma(Y)}$ & $\frac{\sigma(R)}{\sigma(Y)}$ & $\rho(G, Y)$ & $\rho(R, Y)$ \\
\hline \hline & & & & & \\
Chile & $1980: 1-2004: 4$ & 11.3 & 1.7 & - & -0.22 \\
Colombia & $1980: 1-2004: 4$ & 2.2 & 3.7 & 0.35 & 0.27 \\
Hong Kong & $1980: 1-2004: 4$ & 2.5 & 3.1 & -0.21 & 0.33 \\
Hungary & $1980: 1-2004: 4$ & 1.7 & 2.6 & -0.63 & -0.01 \\
Israel & $1980: 1-2004: 4$ & 20.7 & 8.7 & - & -0.02 \\
Korea & $1980: 1-2004: 4$ & 2.4 & 2.1 & -0.04 & -0.36 \\
Mexico & $1980: 1-2004: 4$ & 4.0 & 8.5 & -0.11 & -0.48 \\
Slovak Rep. & $1980: 1-2004: 4$ & 2.3 & 5.1 & - & 0.45 \\
Slovenia & $1980: 1-2004: 4$ & 1.5 & 11.1 & 0.27 & 0.25 \\
South Africa & $1980: 1-2004: 4$ & 1.9 & 3.9 & 0.04 & 0.13 \\
Turkey & $1980: 1-2004: 4$ & 8.3 & - & 0.74 & - \\
India & $1999: 2-2010: 2$ & 5.53 & 1.77 & -0.35 & 0.38 \\
& & & & & \\
\hline \hline
\end{tabular}

Drawing on the evidence from Table 1, Table 2 summarizes the stylized facts that are the focus of the theoretical literature on EME business cycles (Column 2), and the wider EME evidence in Column 3.

\footnotetext{
${ }^{7}$ While Neumeyer and Perri (2005) and Uribe and Yue (2005) state that interest rates are generally counter-cyclical in EMEs, Male (2010) finds this observation not to be universally true particularly among EMEs in Africa, Asia, and Eastern Europe.

${ }^{8} \sigma(Z)$ denotes the standard deviation of variable $Z$ and $\rho(Z, Y)$ is the contemporaneous correlation of variable $Z$ with output, $Y$. For India, we obtain the moments from Ghate et al. (2013).
} 
Table 2: Facts based on the wider literature on EME business cycles

\begin{tabular}{lcc}
\hline \hline Variables & Evidence from NP and $\mathrm{AG}^{9}$ & Wider evidence from Male $^{10}$ \\
\hline$\frac{\sigma(C)}{\sigma(Y)}$ & $>1$ & $>1$ \\
$\rho\left(\frac{N X}{Y}, Y\right)$ & $<0$ & $<0$ \\
$\rho(R, Y)$ & $<0$ & $\gtrless 0$ \\
$\rho(G, Y)$ & No Role & $\gtrless 0$ \\
\hline \hline
\end{tabular}

Given Tables 1 and 2, we build a small open economy RBC model which allows us to understand the causal link between the nature of counter-cyclical / a-cyclical fiscal policy, pro-cyclical / counter-cyclical real interest rates, counter-cyclical net exports, and higher relative consumption volatility. Our is therefore a more general framework to understand the wider EME evidence on business cycles.

\section{$1.1 \quad$ Description and Main Results}

We develop a small open economy (SOE) real business cycle (RBC) model along the lines of Neumeyer and Perri (2005) with two crucial differences.

First, we extend their framework by incorporating fiscal policy. We incorporate two different roles for fiscal policy: the government provides public consumption with the private and public components of consumption substitutable; and, the government lends a portion of the working capital constraint faced by the firm at a subsidized interest rate. We assume that the government imposes time invariant distortionary taxes on consumption, labor income and capital income, and maintains a balanced budget at every time period.

Second, unlike Neumeyer and Perri (2005), where agents have GHH preferences, in our framework, agents are assumed to have Cobb-Douglas (CD) utility functions. The assumption of CD preferences permits a shock to the real interest rate to have income effects on labor supply through consumption.

In this paper we show that these added features make the real interest rate less countercyclical or even pro-cyclical at times. Fiscal policy affects the transmission of interest rate shocks onto the real economy through a standard inter-temporal substitution effect, and a time varying wedge which we denote as the fiscal policy wedge. We show that the fiscal policy wedge is a more general version of the simple intra-temporal tax wedge that distorts labor hours in the standard stochastic growth model. Our theoretical contribution is two-fold: first, we characterize the fiscal policy wedge in closed-form under a variety of assumptions on fiscal

\footnotetext{
${ }^{9} \mathrm{NP}$ stands for Neumeyer and Perri (2005) and AG stands for Aguiar and Gopinath (2007).

${ }^{10}$ See Male (2010)
} 
policy, and show how this affects movements in labor supply adversely; and second, we show that because the fiscal policy wedge is time varying and increases with a positive interest rate shock, the impact of an increase of the wedge on labor supply is higher when there is a higher weight on government consumption in utility. This happens because of two effects. First, when an economy is hit with an interest rate shock labor supply falls because of an increase in the fiscal policy wedge. The fiscal policy wedge increases by more when households value public consumption highly. Second, a higher weight on public consumption in utility induces a strong standard inter-temporal substitution effect which reduces private consumption and increases labor supply. The net effect on labor market outcomes of a positive interest rate shock therefore depends on the relative strength of these two individual effects. In general, the net effect will be positive (i.e., equilibrium employment and output increase). ${ }^{11}$

We also show that fiscal policy's second role in our model - to subsidize working capital dampens the reduction in labor demand due to a positive interest rate shock in the standard Neumeyer and Perri (2005) setup. Thus, both labor supply and labor demand channels make the real interest rate a-cyclical, and under certain cases, pro-cyclical, matching the qualitative features of the EME data in Table $2 .^{12}$

\subsubsection{Indian Business Cycle}

We calibrate our model to India. ${ }^{13}$ We choose India because India typifies the broader EME business cycle experience listed in Column 3 (Table 2). The key Indian stylized facts are: higher relative consumption volatility, higher relative investment volatility, counter-cyclical net exports, counter-cyclical government expenditures, and a pro-cyclical interest rate (see Ghate et al. (2013), Table 5). ${ }^{14}$ The counter-cyclicality of government expenditures has been coupled with pro-cyclical interest rates and counter-cyclical next exports, consistent with the evidence on other EMEs reported in Table 1 and Table 2. There is no robust estimate for labor hours on the Indian economy. However, as we will show later, because equilibrium output depends on labor market outcomes, analyzing changes in equilibrium output are sufficient from the standpoint of determining co-movements. We also believe that the specification of fiscal policy in this paper is particularly relevant for India (and other EMEs). For instance, although there have been major financial sector reforms, public

\footnotetext{
${ }^{11}$ The counter-cyclicality of government spending is also consistent with the theoretical prediction of government spending in the neo-classical framework where we would expect to see government consumption move counter-cyclically, if public and private components are substitutes. See Lane (2003).

${ }^{12}$ Our results are consistent with many papers in the literature which argue that the final effect of the simple inter-temporal tax wedge on hours worked depends crucially on whether public consumption is perceived as highly substitutable by agents (see Prescott, 2002).

${ }^{13}$ We calibrate our model using Dynare Version 4.3.0.

${ }^{14}$ These tables have been generated using quarterly data from 1999-Q2 - 2010-Q2.
} 
sector banks still own $70 \%$ of the banking sector's assets in India. ${ }^{15}$ These banks extend priority sector lending to certain sectors such as agriculture, exports, infrastructure and small and medium enterprises (SMEs) at a subsidized lending rate. Government consumption expenditures, in recent years, has also approximated $12 \%$ of GDP in recent years ${ }^{16}$ suggesting its role as a plausible channel through which interest rate shocks are propagated in the model.

\section{The Model}

\subsection{The Firm's Problem}

The economy consists of firms, a government, and households. At any given time $t$ a representative firm produces final output using labor employed at time $t$ and capital carried forward from time period $t-1$. However, prior to actual production, the firm needs to pay a portion $\theta \in[0,1]$ of its total wage bill in advance. To meet this working capital constraint, the firm borrows from the government and from households by issuing debt. ${ }^{17}$ The firm issues corporate bonds to households to whom they promise a return of $R_{t-1}^{P}$ which is a mark-up over the existing international interest rate $R_{t-1}^{*}$. Firms can also borrow from the government at a subsidized interest rate $R_{t-1}^{P}(1-s)$ where $0 \leq s<1$ is the subsidy. We assume however that only a fixed portion, $\theta_{G}$, of the total firm's working capital constraint, $\theta$, such that $\theta_{G} \leq \theta$ can be borrowed from the government at the subsidized rate. The rest of the working capital constraint $\left(\theta-\theta_{G} \geq 0\right)$ has to be covered by issuing bonds in international capital markets at $R_{t-1}^{P}$.

The firm hires labor $\left(l_{t}\right)$ and uses capital $\left(k_{t-1}\right)$ accumulated in time period $t-1$ to produce the final output $y_{t}$ such that

$$
\begin{aligned}
y_{t} & =A_{t} k_{t-1}^{\alpha} l_{t}^{1-\alpha}(1+\gamma)^{t(1-\alpha)} \\
& =A_{t} k_{t-1}^{\alpha}\left[(1+\gamma)^{t} l_{t}\right]^{1-\alpha}, \quad 0<\alpha<1
\end{aligned}
$$

where $(1+\gamma)^{t}$ is labor augmenting technical progress in time period $t$. We assume that the production technology, $y_{t}$, exhibits constant returns to scale (CRS). The firm's profits are given by:

$$
\pi_{t}=y_{t}-w_{t} l_{t}-r_{t} k_{t-1}-\left(R_{t-1}^{G}-1\right) \theta_{G} w_{t} l_{t}-\left(R_{t-1}^{P}-1\right)\left(\theta-\theta_{G}\right) w_{t} l_{t}
$$

\footnotetext{
${ }^{15}$ Table no. 3.1, statistical tables relating to banks of India, Handbook of Statistics of the Indian Economy, 2012 (http://www.rbi.org.in/scripts/PublicationsView.aspx?id=14672).

${ }^{16}$ See the 2013 World Development Indicators: http://data.worldbank.org/indicator/NE.CON.GOVT.ZS

${ }^{17}$ In Neumeyer and Perri (2005), firms cannot borrow from the government.
} 
The last two terms in (2) denote the interest costs for working capital loans from the government and households, respectively, where $R_{t-1}^{P}$ is the country specific gross interest rate at which firms borrow from international capital markets, and $R_{t-1}^{G}$ is the subsidized gross interest rate offered by the government to lend ' $\theta_{G}$ ' portion of the firm's total working capital constraint. No-arbitrage implies:

$$
R_{t-1}^{G}=R_{t-1}^{P}(1-s)>1, \quad 0 \leq s<1
$$

Here $R_{t-1}^{G}>1$ since it is the gross interest rate. We can therefore re-write equation (2) as

$$
\pi_{t}=y_{t}-r_{t} k_{t-1}-(1-\theta) w_{t} l_{t}-w_{t} l_{t} R_{t-1}^{P}\left[\theta-s \theta_{G}\right]
$$

The partially subsidized loan provided by the government to cover the firm's working capital constraint therefore effectively creates a wedge $\left[\theta-s \theta_{G}\right]$ on the interest payment. Clearly, if $s=0$, we go back to the standard Neumeyer and Perri (2005) model. ${ }^{18}$

Timing of Events The timing of events and decisions is given in Figure (1). In the beginning of period $t$, which we denote as $t^{-}$, firms borrow, $\theta w_{t} l_{t}$, to make advance payments to labor prior to actual production (which occurs at $t$ ). Firms then produce output and repay the loan borrowed at the end of time period $\left(t^{+}\right)$, with workers receiving the rest of their wage bill, $(1-\theta) w_{t} l_{t}$, at time $t^{+}$also. Since the time gap between $t^{-}$and $t$, and between $t$ and $t^{+}$is very small, we drop these superscripts and consider the entire period as time period $t$.

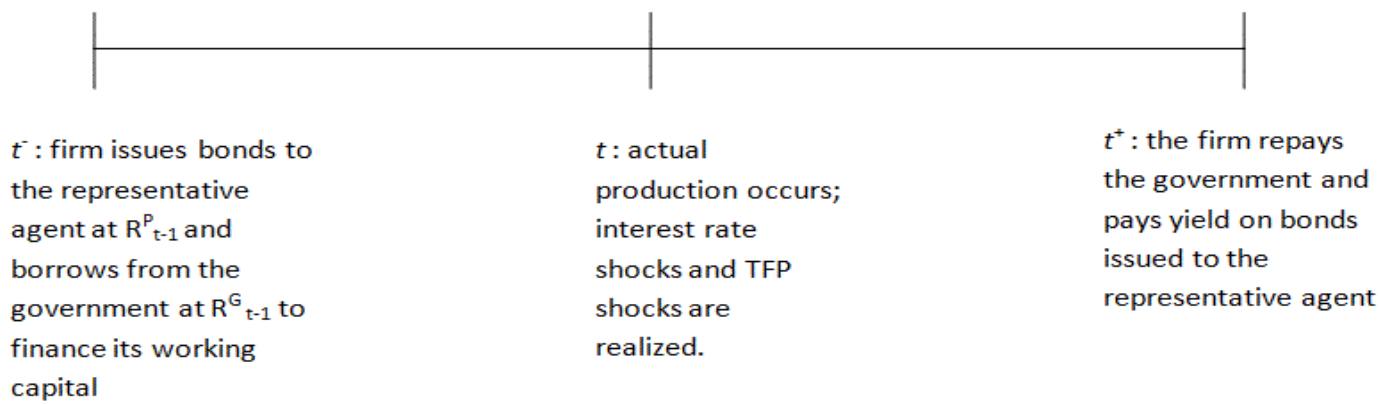

Figure 1: Timing of Events and Decisions

\footnotetext{
${ }^{18}$ As in Neumeyer and Perri (2005), country specific interest rates depend on the international interest rate and country specific spread component which measures the economy's riskiness.
} 
We transform output $y_{t}$ to it's stationary value $\widetilde{y}_{t}$, as follows ${ }^{19}$

$$
\begin{aligned}
\widetilde{y}_{t} & =\frac{y_{t}}{(1+\gamma)^{t}}=\frac{A_{t} k_{t-1}^{\alpha} l_{t}^{1-\alpha}(1+\gamma)^{t(1-\alpha)}}{(1+\gamma)^{t}} \\
& =A_{t} \frac{k_{t-1}^{\alpha}}{\left[(1+\gamma)^{t}\right]^{\alpha}} l_{t}^{1-\alpha} \\
& =\frac{A_{t}}{(1+\gamma)^{\alpha}} \widetilde{k}_{t-1}^{\alpha} l_{t}^{1-\alpha} .
\end{aligned}
$$

Hence, equation (4) can be re-written as

$$
\widetilde{\pi}_{t}=\widetilde{y}_{t}-\frac{r_{t} \widetilde{k}_{t-1}}{(1+\gamma)}-(1-\theta) \widetilde{w}_{t} l_{t}-\widetilde{w}_{t} l_{t} R_{t-1}^{P}\left[\theta-s \theta_{G}\right] .
$$

\subsubsection{Firms Profit Maximizing Conditions}

The firm's profit maximization yields the following first order conditions $\forall t$, for labor, $l_{t}$, and capital, $\widetilde{k}_{t-1}$, respectively.

$$
\begin{aligned}
\left\{l_{t}\right\} & : \frac{(1-\alpha) \widetilde{y}_{t}}{l_{t}}=\widetilde{w}_{t}\left[(1-\theta)+R_{t-1}^{P}\left(\theta-s \theta_{G}\right)\right] \\
\left\{\widetilde{k}_{t-1}\right\} & : \frac{\alpha \widetilde{y}_{t}}{\widetilde{k}_{t-1}}=\frac{r_{t}}{(1+\gamma)} .
\end{aligned}
$$

Without any working capital constraints, $\theta=\theta_{G}=0$, and the standard first order condition for labor demand, $\frac{(1-\alpha) \widetilde{y}_{t}}{l_{t}}=\widetilde{w}_{t}$, obtains. The presence of the working capital constraint therefore modifies this condition by changing the effective wage payment to, $\widetilde{w}_{t}\left[(1-\theta)+R_{t-1}^{P}\left(\theta-s \theta_{G}\right)\right]$. For given values of $\theta$ and $\theta_{G}$, interest rate shocks affect wage payments with a lag since effective wage payments depend on $R_{t-1}^{P}$.

\subsection{Government}

The government collects tax revenue by imposing time invariant distortionary taxes on consumption $\tau_{c} \in[0,1]$, wage income $\tau_{w} \in[0,1]$, and capital income $\tau_{k} \in[0,1]$. It also receives interest income from financing the ' $\theta_{G}$ ' component of a firm's working capital constraint.

\footnotetext{
${ }^{19}$ For any variable $x_{t}$, we define it's stationary transformation as $\widetilde{x}_{t}$ such that,

$$
\widetilde{x}_{t}=\frac{x_{t}}{(1+\gamma)^{t}}
$$

All variables in our model grow at the same exogenous rate $(1+\gamma)$. All variables are therefore transformed to their corresponding stationary values except $l_{t}$, which is assumed to be stationary.
} 
The interest income is given by, $R_{t-1}^{G} \theta_{G} w_{t} l_{t}$. The government allocates $G_{t}$ of it's total revenue towards government consumption. We assume that net of $G_{t}$, the government lends $S_{t}$ to firms at time period $t$ at a subsidized interest rate given by (3). The government is assumed to balance it's budget at every time period $t$ such that

$$
T R_{t}+R_{t-1}^{G} \theta_{G} w_{t} l_{t}=G_{t}+S_{t}
$$

$T R_{t}$ denotes the total tax revenue collected by the government at every time period such that

$$
T R_{t}=\tau_{c} c_{t}+\tau_{w} w_{t} l_{t}+\tau_{k} r_{t} k_{t-1} .
$$

As discussed above, due to the timing of the firm's problem, we have

$$
S_{t}=\theta_{G} w_{t} l_{t}
$$

Clearly, this implies ${ }^{20}$

$$
G_{t}=\tau_{c} c_{t}+\left\{\left[R_{t-1}^{P}(1-s)-1\right] \theta_{G}+\tau_{w}\right\} w_{t} l_{t}+\tau_{k} r_{t} k_{t-1}
$$

\subsection{The Household's Problem}

The economy is populated by infinitely lived households with a mass normalized to 1. Each representative household consumes and invests a homogenous good and supplies labor and capital to firms. The representative household has the following expected discounted lifetime utility

$$
E_{0} \sum_{t=0}^{\infty} \beta^{t} U\left(c_{t}^{*}, l_{t}\right),
$$

where $\beta \in(0,1)$ denotes the households subjective discount factor. We assume that

$$
c_{t}^{*}=c_{t}+\Theta G_{t}
$$

where household consumption, $c_{t}$ is augmented by government consumption, $G_{t}$. Following Barro (1981), Ni (1995), Roche (1996), Ambler and Paquet (1996), and Christiano and Eichenbaum (1992) the parameter $\Theta$ captures the weight of public consumption in household

${ }^{20}$ The stationary transformation of equation (7) is:

$$
\widetilde{G}_{t}=\tau_{c} \widetilde{c}_{t}+\left\{\left[R_{t-1}^{P}(1-s)-1\right] \theta_{G}+\tau_{w}\right\} \widetilde{w}_{t} l_{t}+\frac{\tau_{k} r_{t} \widetilde{k}_{t-1}}{1+\gamma}
$$


utility, where $\Theta>0$. Given our specification in equation (9), $c_{t}$ and $G_{t}$ are assumed to be perfect substitutes. ${ }^{21}$ We assume that agents treat $G_{t}$ as given. $l_{t}$ denotes hours worked.

We parametrize the utility function, $U$, in (8) by assuming a Cobb-Douglas (CD) specification, i.e.,

$$
U\left(c_{t}^{*}, l_{t}\right)=\frac{\left[\left(c_{t}^{*}\right)^{\mu}\left(1-l_{t}\right)^{(1-\mu)}\right]^{(1-\sigma)}}{(1-\sigma)}, \quad 0<\mu<1, \sigma>0 .
$$

which is an important point of departure from Neumeyer and Perri (2005). These authors, instead, assume GHH preferences because their focus was to explain counter-cyclicality of interest rates in the select EMEs that they consider. Assuming GHH preferences ensures that labor supply is independent of consumption and therefore interest rates. A positive shock to the interest rates does not cause any shift in the labor supply while it reduces demand for labor thereby reducing equilibrium labor. This leads to a reduction in output which makes real interest rates counter-cyclical with respect to output. We focus on the Cobb-Douglas (CD) utility function to allow equilibrium labor to increase due to a single period interest rate shock for some parametric restrictions. The parameter $\sigma$ is the coefficient of risk aversion and $\mu$ is the intra-temporal elasticity of substitution of labor supply.

The representative household maximizes expected lifetime discounted utility (8) subject to

$$
\left(1+\tau_{c}\right) c_{t}+x_{t}+b_{t}+\kappa\left(b_{t}\right) \leq\left(1-\tau_{w}\right) w_{t} l_{t}+\left(1-\tau_{k}\right) r_{t} k_{t-1}+R_{t-1}^{P} b_{t-1}
$$

where $b_{t}$ denotes bond holdings of the household, $x_{t}$ denotes investment, and $\tau_{c} \in[0,1]$ is the tax on consumption, $\tau_{w} \in[0,1]$ is the tax on labor income, and $\tau_{k} \in[0,1]$ is the tax on capital income. Agents take the competitive factor awards, $w_{t}$, the wage rate, and $r_{t}$, the return to capital as given in deciding optimal choices. For bond holdings, $b_{t}$, the term $\kappa\left(b_{t}\right)$ in (10) is the bond holding cost such that

$$
\kappa\left(b_{t}\right)=\frac{\kappa}{2} y_{t}\left[\left(\frac{b_{t}}{y_{t}}\right)-\left(\frac{b}{y}\right)\right]^{2}
$$

The term $x_{t}$ in (10) is the level of private investment such that

$$
x_{t}=k_{t}-(1-\delta) k_{t-1}+\Phi\left(k_{t}, k_{t-1}\right) \text {, }
$$

\footnotetext{
${ }^{21}$ In an emerging market context, an example of $G_{t}$ can be public health or public transportation services whose quality is typically seen as being superior to private alternatives. Higher provision of services elicits a strong reduction in the private consumption of these services. See Kuehlwein (1998).
} 
where $\Phi\left(k_{t}, k_{t-1}\right)$ is the investment adjustment costs such that

$$
\Phi\left(k_{t}, k_{t-1}\right)=\frac{\phi}{2} k_{t-1}\left[\left(\frac{k_{t}}{k_{t-1}}\right)-(1+\gamma)\right]^{2}
$$

Households First Order Conditions We obtain the following first order conditions $\forall t$, by solving the representative agent's competitive equilibrium problem, where $\widetilde{\beta}=\beta(1+\gamma)^{\mu(1-\sigma)}$,

$$
\left\{\widetilde{c}_{t}\right\}: \lambda_{t}\left(1+\tau_{c}\right)=\left[\left(\widetilde{c}_{t}^{*}\right)^{\mu}\left(1-l_{t}\right)^{(1-\mu)}\right]^{-\sigma} \mu\left(\widetilde{c}_{t}^{*}\right)^{\mu-1}\left(1-l_{t}\right)^{(1-\mu)},
$$

and where $\lambda_{t}$ is the Lagrangian multiplier. The first order condition for labor supply is given by

$$
\left\{l_{t}\right\}: \lambda_{t}\left(1-\tau_{w}\right) \widetilde{w}_{t}=\left[\left(\widetilde{c}_{t}^{*}\right)^{\mu}\left(1-l_{t}\right)^{(1-\mu)}\right]^{-\sigma}(1-\mu)\left(\widetilde{c}_{t}^{*}\right)^{\mu}\left(1-l_{t}\right)^{-\mu} .
$$

From (14) and (15) we get

$$
\left(1-l_{t}\right)=\left(\frac{1-\mu}{\mu}\right)\left(\frac{1+\tau_{c}}{1-\tau_{w}}\right)\left(\frac{\widetilde{c}_{t}^{*}}{\widetilde{w}_{t}}\right)
$$

The first order condition with respect to $b_{t}$ is given by

$$
\left\{\widetilde{b}_{t}\right\}: 1+\kappa\left[\frac{\widetilde{b}_{t}}{\widetilde{y}_{t}}-\frac{b}{y}\right]=E_{t}\left[\frac{\widetilde{\beta}}{(1+\gamma)} \frac{\lambda_{t+1}}{\lambda_{t}} R_{t}^{P}\right]
$$

Finally the first order condition with respect to $k_{t}$ is given by

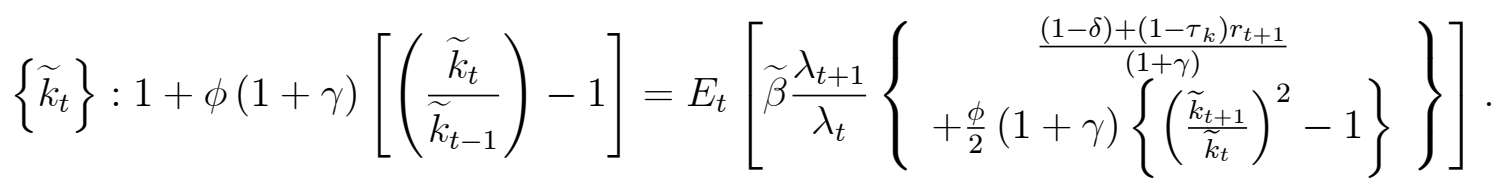

Competitive Equilibrium A competitive equilibrium of our model is defined as follows.

Definition 1 Given $\left\{A_{t} \text { and } R_{t}^{P}\right\}_{t=0}^{\infty}$, a vector of fiscal policy parameters $\left\{\tau_{c}, \tau_{k}, \tau_{w}, \theta_{G}, s, \Theta\right\}$, and initial conditions $\widetilde{k}_{-1}, \widetilde{b}_{-1}, R_{-1}^{P}$, a competitive equilibrium is a vector of allocations of $\left\{\widetilde{c}_{t}, \widetilde{k}_{t}, \widetilde{b}_{t}, l_{t} \text { and } \widetilde{G}_{t}\right\}_{t=0}^{\infty}$ and factor prices $\left\{\widetilde{w}_{t} \text { and } r_{t}\right\}_{t=0}^{\infty}$ such that, for the given sequence of factor prices, $(i)\left\{\widetilde{k}_{t} \text { and } l_{t}\right\}_{t=0}^{\infty}$ solves the firm's profit maximization problem (4) and (5), (ii) $\left\{\widetilde{c}_{t}, \widetilde{k}_{t}, \widetilde{b}_{t}, l_{t}\right\}_{t=0}^{\infty}$ maximizes the utility of the representative agent (8) subject to (1), (10), (9), (11), (12) and (13), together with $\widetilde{c}_{t}, \widetilde{k}_{t} \geqslant 0$, (iii) $\widetilde{G}_{t}$ satisfies (7), (iv) a no-Ponzi associated with the initial conditions $k_{-1}$ and $b_{-1}$ holds for the representative agent, and finally, (v) all markets clear $\forall t$. 


\subsection{The steady state}

From the firm's first order conditions (5), at the steady state we obtain

$$
\frac{\bar{y}}{\bar{r} \bar{k}}=\frac{1}{(1+\gamma) \alpha}
$$

and

$$
(1-\alpha) \bar{y}=\bar{w} \bar{l}\left[(1-\theta)+\bar{R}^{P}\left(\theta-s \theta_{G}\right)\right] .
$$

From equation (16), at steady state, labor supply is given as

$$
(1-\bar{l})=\left(\frac{1-\mu}{\mu}\right)\left(\frac{1+\tau_{c}}{1-\tau_{w}}\right)\left(\frac{\bar{c}+\Theta \bar{G}}{\bar{w}}\right)
$$

which implies

$$
\bar{l}=1-\left(\frac{1-\mu}{\mu}\right)\left(\frac{1+\tau_{c}}{1-\tau_{w}}\right)\left(\frac{\bar{c}+\Theta \bar{G}}{\bar{w}}\right)
$$

where $\bar{c}, \bar{G}, \bar{y}$ and $\bar{w}$ are steady levels of consumption, government consumption, output and the wage rate respectively. ${ }^{22}$ From the first order conditions for the representative agent with respect to bonds (17), at the steady state, we obtain

$$
\bar{R}^{P}=\frac{(1+\gamma)}{\widetilde{\beta}}
$$

This implies

$$
\bar{R}^{P}=\frac{(1+\gamma)}{\widetilde{\beta}}>(1+\gamma)
$$

since

$$
0<\widetilde{\beta}<1
$$

From the first order conditions for the representative agent with respect to capital (18), at the steady state, we obtain the following arbitrage condition between $\bar{r}$ and $\bar{R}^{P}$

$$
\bar{r}=\frac{\bar{R}^{P}-(1-\delta)}{\left(1-\tau_{k}\right)} .
$$

In sum, the steady state of this economy is given by equation (19), (20), (21), (22) and (23). ${ }^{23}$

\footnotetext{
${ }^{22}$ See the Appendix for details on the steady state of the economy.

${ }^{23}$ See Appendix for other steady state equations.
} 


\subsection{The Fiscal Policy Wedge}

This section derives the fiscal policy wedge for the model, and shows how the impact of interest rate shocks on labor market outcomes is mitigated by the presence of the wedge.

\subsubsection{The effect of interest rate shocks on labor supply}

Note that from equation (16), and unlike the case with GHH preferences, labor supply depends on current levels of effective consumption, $\widetilde{c}_{t}^{*}$ because of the income effect, and $\widetilde{w}_{t}$. The following Proposition shows that $l_{t}^{S}$ can be expressed as a function of consumption, wages and a time varying fiscal policy wedge, which we denote by, $\Gamma_{t}>1$.

Proposition 1 Labor supply, $l_{t}^{S}$, is given by:

$$
l_{t}^{S}=1-\frac{\widetilde{c}_{t}}{\widetilde{w}_{t}}\left(\frac{1-\mu}{\mu}\right) \Gamma_{t}
$$

where

$$
\Gamma_{t}=\left(\frac{1+\tau_{c}}{1-\tau_{w}}\right) \frac{\Psi_{t}}{D_{t-1}}
$$

and

$$
\begin{aligned}
D_{t-1} & =1+\Theta\left(\frac{1-\mu}{\mu}\right)\left(\frac{1+\tau_{c}}{1-\tau_{w}}\right)\left\{\left[R_{t-1}^{P}(1-s)-1\right] \theta_{G}+\tau_{w}\right\} \\
\Psi_{t} & =\left[1+\Theta \tau_{c}+\frac{\Theta \tau_{k} r_{t} \widetilde{k}_{t-1}}{(1+\gamma) \widetilde{c}_{t}}+\frac{\Theta\left\{\left[R_{t-1}^{P}(1-s)-1\right] \theta_{G}+\tau_{w}\right\} \widetilde{w}_{t}}{\widetilde{c}_{t}}\right] .
\end{aligned}
$$

Further, suppose $\tau_{c}>\tau_{w}, \tau_{c}>\left[R_{t-1}^{P}(1-s)-1\right] \theta_{G}$, and $\mu>0.5$. This implies that $\Gamma_{t}>1$.

Proof. See Appendix.

The above proposition derives sufficient conditions under which $\Gamma_{t}>1$. From (25), the presence of the fiscal policy wedge reduces labor supply relative to the case $\Gamma_{t}=1$. Note also that from (25), $\Gamma_{t}$ depends upon the fiscal policy parameters $\tau_{k}, \tau_{w}, \tau_{c}, s, \theta_{G}$, and $\Theta$. This implies that the fiscal policy wedge is not just sensitive to the tax rates but also to the subsidy given to the firms.

The above proposition formalizes the mechanism through which interest rate shocks affect labor market outcomes. From equation (24), interest rate shocks affect labor supply through two channels in time period, $t$. A positive interest rate shock causes consumption, $\widetilde{c}_{t}$, to instantaneously fall due to the standard inter-temporal substitution effect (equation (17)). Figure (2) illustrates the effect of a single period shock to $R_{t}^{P}$ on labor supply. 


\section{[INSERT FIGURE (2)]}

As can be seen in Proposition 1, the fiscal policy wedge, $\Gamma_{t}$, consists of two time varying variables $D_{t-1}$ and $\Psi_{t}$. The variable $D_{t-1}$ does not change on impact because it depends on $R_{t-1}^{P}$, that is, the interest rate that prevailed in time period $t-1$. The variable $\Psi_{t}$ however increases in time period $t$ due to a reduction in $\widetilde{c}_{t}$ and an increase in $r_{t}$ (through the no arbitrage condition). As a result, the fiscal policy wedge, $\Gamma_{t}$, increases on impact due to a positive interest rate shock. Also, for a higher value of $\Theta$, the increase in the fiscal policy wedge is higher for a given interest rate shock. We therefore obtain the following Proposition

Proposition 2 For a positive shock to $R_{t}^{P}$

$$
\frac{\partial \widetilde{c}_{t}}{\partial R_{t}^{P}}<0 \Longrightarrow \frac{\partial l_{t}^{S}}{\partial R_{t}^{P}}>0
$$

Further, a positive interest rate shock always increases the fiscal policy wedge, i.e., $\frac{\partial \Gamma_{t}}{\partial R_{t}^{P}}>0$, with the effect stronger for a higher $\Theta$. An increase in $\Gamma_{t}$ therefore dampens the outward shift of the labor supply:

$$
\left|\frac{\partial l_{t}^{S}}{\partial R_{t}^{P}}\right|_{\Gamma_{t}=1}>\left|\frac{\partial l_{t}^{S}}{\partial R_{t}^{P}}\right|_{\Gamma_{t}>1}>0 .
$$

Figure (3) illustrates how $\Gamma_{t}$ dampens the effect of a single period shock to $R_{t}^{P}$ on labor supply.

\section{[INSERT FIGURE (3)]}

Labor supply moves out to $L^{S^{\prime \prime}}$ instead of $L^{S^{\prime}}$ due to an increase in $\Gamma_{t}$. With CobbDouglas preferences, the labor supply moves outward as a result of an interest rate shock because consumption drops instantaneously. This is the standard inter-temporal substitution effect, and it is strengthened with a higher value of $\Theta$. This happens because a higher value of $\Theta$ implies a higher weight on government consumption in utility which allows households to reduce their private consumption more and push current consumption to the future. However, because of the simultaneous increase in $\Gamma_{t}$, a rise in $\Gamma_{t}$ reduces labor supply because an increase in the fiscal policy wedge makes consumption more expensive in terms of leisure. The net increase in labor supply is therefore determined by the inter-temporal substitution effect and the fiscal policy wedge, $\Gamma_{t}$. When $\Theta$ is high, the inter-temporal substitution effect has a stronger effect on labor supply than the fiscal policy wedge. This causes a larger net increase in labor supply in time period, $t$. When $\Theta$ is small $(<1)$, the inter-temporal substitution effect has a smaller effect on labor supply than the fiscal policy wedge. This 
causes a smaller net increase in labor supply in time period, $t$. Importantly, in time period, $t$, equilibrium labor always increases.

Note that the fiscal policy wedge, $\Gamma_{t}$, is time varying because government consumption directly affects the household's effective consumption $\widetilde{c}_{t}^{*}$. Under certain conditions however, the fiscal policy wedge will be constant and greater than 1 . This constancy of the wedge implies interest rate shocks will affect labor supply only through consumption, $\widetilde{c}_{t}$, and not the fiscal policy wedge. Remark 1 summarizes these conditions.

Remark $1 \quad \Gamma_{t}$ will be a constant under different specifications of fiscal policy. When there is no fiscal policy, i.e.,

$$
\begin{gathered}
\tau_{k}=\tau_{w}=\tau_{c}=0 \\
s=\theta_{G}=\Theta=0 \\
\Rightarrow \Gamma_{t}=\bar{\Gamma}=1, \forall t
\end{gathered}
$$

When $\widetilde{G}_{t}$ does not affect $\widetilde{c}_{t}^{*}$ or if the government provided a lump-sum income transfer instead to the representative agent, in which case, the fiscal policy wedge is the standard intratemporal tax wedge, i.e.,

$$
\begin{aligned}
\Theta & =0 \\
& \Rightarrow \Gamma_{t}=\bar{\Gamma}=\left(\frac{1+\tau_{c}}{1-\tau_{w}}\right), \forall t
\end{aligned}
$$

Under GHH preferences, $\Gamma_{t}$, is given $b y^{24}$

$$
\Gamma_{t}=\bar{\Gamma}=\left(\frac{1-\tau_{w}}{1+\tau_{c}}\right)^{\frac{1}{v-1}} \forall t
$$

\subsubsection{The effect of interest rate shocks on labor demand}

From equation (4), we can show that the demand for labor is given by

$$
l_{t}^{D}=\frac{(1-\alpha) \widetilde{y}_{t}}{\widetilde{w}_{t}\left[(1-\theta)+R_{t-1}^{P}\left(\theta-s \theta_{G}\right)\right]},
$$

${ }^{24}$ In this case, $U\left(\widetilde{c}_{t}^{*}, l_{t}\right)=\frac{\left[\widetilde{c}_{t}^{*}-\psi l_{t}^{v}\right]^{(1-\sigma)}}{(1-\sigma)}$, and the first order conditions yields:

$$
\left(\frac{1-\tau_{w}}{1+\tau_{c}}\right) \widetilde{w}_{t}=\psi v\left(l_{t}^{s}\right)^{v-1}
$$


which can be re-written as

$$
l_{t}^{D}=\left[\frac{(1-\alpha) A_{t}}{\widetilde{w}_{t}\left[(1-\theta)+R_{t-1}^{P}\left(\theta-s \theta_{G}\right)\right]}\right]^{\frac{1}{\alpha}} \frac{\widetilde{k}_{t-1}}{(1+\gamma)} .
$$

An increase in $R_{t}^{P}$ causes the labor demand curve $l^{D}$ to shift inwards only in time period $t+1$, that is,

$$
\frac{\partial l_{t+1}^{D}}{\partial R_{t}^{P}}=-\frac{l_{t+1}^{D}\left(\theta-s \theta_{G}\right)}{\alpha\left[(1-\theta)+R_{t}^{P}\left(\theta-s \theta_{G}\right)\right]} .
$$

This is shown in the following figure (4).

\section{[INSERT FIGURE (4)]}

The presence of the subsidy parameters $\theta_{G}$ and $s$ however dampens the inward shift of $l_{t+1}^{D}$. As shown in figure (5), if the government increases $\theta_{G}$ or $s$, the reduction in $l_{t+1}^{D}$ is less, and the new labor demand curve is $L^{D^{\prime \prime}}$ and not $L^{D^{\prime}}$.

\section{[INSERT FIGURE (5)]}

Proposition 3 summarizes the effect of a single period shock $R_{t}^{P}$ on labor demand.

Proposition 3 A positive shock to interest rate $R_{t}^{P}$ lowers labor demand only in time period $t+1$. However, the presence of $\theta_{G}$ and $s$, dampens the reduction in $l_{t+1}^{D}$. That is

$$
\left|\frac{\partial l_{t+1}^{D}}{\partial R_{t}^{P}}\right|_{s \neq 0, \theta_{G} \neq 0}<\left|\frac{\partial l_{t+1}^{D}}{\partial R_{t}^{P}}\right|_{s=0, \theta_{G}=0} .
$$

Proof. See Appendix.

Therefore from Proposition 2 and Proposition 3 we obtain the impact of a single period positive interest rate shock on equilibrium labor and output in time period $t$. This is shown in Proposition 4

Proposition 4 Equilibrium labor $l_{t}$ increases on impact due to a positive shock to $R_{t}^{P}$. This causes output $y_{t}$ to increase on impact, that is,

$$
\frac{\partial \widetilde{y}_{t}}{\partial R_{t}^{P}}>0
$$

Fiscal policy dampens the movements in equilibrium labor. This is because an increase in the fiscal policy wedge $\Gamma_{t}$ dampens the outward movement of $l_{t}^{S}$ and the subsidy parameters, $\theta_{G}$ and $s$, dampens the inward movement of $l_{t+1}^{D}$. 
Proof. Follows directly from Proposition 2 and Proposition 3.

The import of Proposition 4 is that in time period $t$, on impact, equilibrium output increases. However, in $t+1$, the labor demand schedule moves downwards which implies that output will rise/fall depending on the magnitude of the fiscal policy wedge, and the policy parameters in the labor demand curve. If the fiscal policy wedge is strong and the subsidy parameters, $\left(s, \theta_{G}\right)$ are small, then a downward movement in labor demand will unambiguously decrease full employment output.

\section{Calibration}

In this section, we calibrate the model to Indian data. Based on the quarterly data available on the Indian macroeconomy documented in Ghate et al. (2013), the stylized facts relevant for the Indian economy $\operatorname{are}^{25}$, (a) higher relative consumption volatility, (b) counter-cyclical net exports, (c) counter-cyclical government expenditures, and (d) a pro-cyclical real interest rate. These facts are based on quarterly data available on the Indian macroeconomy documented in Ghate et al. (2013), for which we seek to replicate qualitatively.

As we noted in the introduction, while the first two facts are common to a wide variety of EMEs, there is no robust stylized observation on the correlation between real government expenditure and output. In some EMEs, government expenditures are counter-cyclical with respect to output and in others it is pro-cyclical. Also, while Neumeyer and Perri (2005) and Uribe and Yue (2005) state that interest rates are generally counter-cyclical in EMEs, Male (2010) finds this observation not to be universally true particularly among EMEs in Africa, Asia and Eastern Europe. In the small sample of EMEs in Neumeyer and Perri (2005), however, the interest rate is counter-cyclical, and there is no role for fiscal policy. Our theoretical model can therefore be seen as providing a more general model that produces a range of business cycle outcomes that are consistent with the broader EME experience.

\subsection{Parameter Values}

We set the exogenous labor augmenting technological progress for India at $\gamma=0.047$ as estimated by Bhattacharya et al. (2013). We fix the quarterly capital depreciation rate at $\delta=0.025$ which approximately matches the annual depreciation rate in India of $10 \%$. We choose $\alpha=0.4$ from Ghate et al. (2012). The capital adjustment cost parameter, $\phi$ has been fixed at 60 . We assume the bond holding cost parameter $\kappa=0.0001$ as in Tiryaki (2012). We arbitrarily fix the value of $\mu$, the share of consumption in the utility function at

\footnotetext{
${ }^{25}$ The sample period is Q2-1999 to Q2-2010
} 
0.75. We fix the value of the discount rate at $\beta=0.99$ and the value of coefficient of risk aversion parameter at $\sigma=2.3$. The choice of $\mu, \beta$ and $\sigma$ are such that the calibrated value of $\bar{R}^{P}$ is approximately consistent with average long run value of the Prime Lending Rates (PLR) of three major banks in India. ${ }^{26}$ We fix the value of $\theta_{G}=\theta=1$ as in Neumeyer and Perri (2005). We choose $\theta_{G} \leq \theta$ according to our choice of $\theta$. In our baseline calibrations, we arbitrarily set $\theta_{G}=1^{27}$, which means that the entire working capital constraint is subsidized. We arbitrarily choose a value of $\Theta>1 .^{28}$ We choose $s$ such that

$$
\bar{R}^{G}=\bar{R}^{P}(1-s)>1
$$

Given that India has a very narrow income tax base and depends more on generating revenue from indirect taxation, we allow for a high tax on consumption and a low income tax (see Poirson (2006)). In particular, the value of $\tau_{c}$ is fixed at 0.12 to match the VAT rate applicable in India. We fix the factor income tax rates low at $\tau_{k}=\tau_{w}=0.01$ which follows the estimated average effective tax rates in Poirson (2006). We also fix $\Theta=5$. Table (3) summarizes our choice of deep parameters in our model. ${ }^{29}$

\footnotetext{
${ }^{26}$ We consider the average nominal PLR of three major banks in India - the State Bank of India SBI, ICICI bank and IDBI bank. We construct the quarterly data from the daily data available for each bank in the CEIC database. For the CEIC database visit http://www.ceicdata.com/en/countries/india. Some of the missing datapoints on the PLR for SBI was obtained using the data published by Reuters India. For Reuters India visit http://in.reuters.com/article/2013/06/10/india-plridINL3N0EM1YU20130610?type=companyNews. We then deflate the quarterly interest rates using the quarterly inflation using the CPI data. See Table 170, Handbook of Statistics of the Indian Economy, RBI. http://www.rbi.org.in/scripts/PublicationsView.aspx?id=14528.

${ }^{27}$ Though we choose $\theta_{G}=1$, the subsidy $s$ is very small, which implies the effective amount of subsidized loan from the government is not very large.

${ }^{28}$ In our baseline calibrations, we arbitrarily fix $\Theta=5$. Since the representative agent takes $G$ as given in every time period, $\Theta>1$ is feasible. A high value of $\Theta$ implies that government consumption is very efficient and the representative agent attaches high weightage to it. As we will show, this assumption is crucial for making consumption more volatile than output in our model.

${ }^{29}$ The rest of our endogenous and exogenous variables are derived at the steady state based on these parameter values.
} 


\begin{tabular}{|c|c|c|}
\hline Parameter Name & Symbol & Value \\
\hline Coefficient of risk aversion (calibrated) & $\sigma$ & 2.3 \\
\hline Share of consumption in utility function (calibrated) & $\mu$ & 0.75 \\
\hline Depreciation rate & $\delta$ & 0.025 \\
\hline $\begin{array}{c}\text { Rate of technical progress } \\
\text { (Bhattacharya et al. (2013)) }\end{array}$ & $\gamma$ & 0.047 \\
\hline Ratio of wage bill to be paid in advance & $\theta$ & 1 \\
\hline Discount rate (calibrated) & $\beta$ & 0.99 \\
\hline Effective discount rate (calibrated) & $\widetilde{\beta}$ & $\beta(1+\gamma)^{\mu(1-\sigma)}$ \\
\hline Real interest rate (calibrated) & $\bar{R}^{P}$ & $\frac{(1+\gamma)}{\widetilde{\beta}}$ \\
\hline $\begin{array}{l}\text { Share of capital in production } \\
\text { (Ghate et al. }(2012) \text { ) }\end{array}$ & $\alpha$ & 0.4 \\
\hline Bond holding costs (Tiryaki (2012)) & $\kappa$ & 0.0001 \\
\hline Capital adjustment costs & $\phi$ & 60 \\
\hline Subsidized portion of the advance wage bill ratio & $\theta_{G}$ & $\leq \theta$ \\
\hline Subsidy on working capital loans & $s$ & 0.1 \\
\hline Tax on consumption (VAT rate in India) & $\tau_{c}$ & 0.12 \\
\hline Tax on labor income (Poirson (2006)) & $\tau_{w}$ & 0.01 \\
\hline Tax on capital income & $\tau_{k}$ & $=\tau_{w}$ \\
\hline Weightage of government consumption in $c_{t}^{*}$ & $\Theta$ & $\geqslant 1$ \\
\hline Steady state TFP & $\bar{A}$ & 1 \\
\hline
\end{tabular}

\subsection{Estimation of the data generating processes}

We calibrate the model using total factor productivity (TFP) shocks and interest rate shocks. We obtain annual data for total factor productivity for the period 1980-2008 from the Penn World Tables version 8.0 (2014). ${ }^{30}$ We use the variable "rtfpna", a TFP index with base year 2005, as reported in the Tables. ${ }^{31}$ The aggregate log-TFP data is then de-trended using a HP-Filter using a standard annual smoothing parameter equal to 100 such that

$$
\begin{aligned}
\widehat{A}_{t} & =\rho_{A} \widehat{A}_{t-1}+\varepsilon_{t A}, \\
\text { where } \rho_{A} & =0.42
\end{aligned}
$$

with a standard error of regression $\sigma_{A}=0.012 . \widehat{A}_{t}$ is the de-trended log-TFP data.

\footnotetext{
${ }^{30}$ See http://www.rug.nl/research/ggdc/data/penn-world-table

${ }^{31}$ For 2005 , rtfpna $=1$.
} 
To estimate the data generating process for real interest rates, we use the annual real interest rates data published by World Bank for the period 1980 - 2008. We choose annual data to maintain consistency in the frequency across all data generating processes. ${ }^{32}$ The domestic interest rate on bonds is modelled as a mark-up on the world interest rate, i.e.,

$$
R_{t}^{P}=R_{t}^{*} D_{t}
$$

where $R_{t}^{P}$ is the gross domestic real lending rate in India and $R_{t}^{*}$ is the world interest rate which is assumed to be the US gross real lending rate. $D_{t}$ is the country spread over $R_{t}^{*}$. ${ }^{33}$ We de-trend the gross real interest rate data using a standard annual smoothing parameter equal to 100 such that

$$
\widehat{R}_{t}^{P}=\widehat{R}_{t}^{*}+\widehat{D}_{t}
$$

where a variable $\widehat{x}_{t}$ is the de-trended value of $x_{t}$ from its steady state $\bar{x}$. We then estimate an $\operatorname{AR}(1)$ process on $\widehat{R}_{t}^{*}$ is an $\operatorname{AR}(1)$ process to be

$$
\widehat{R}_{t}^{*}=\rho_{R} \widehat{R}_{t-1}^{*}+\varepsilon_{t R}
$$

where $\rho_{R}=0.462$

with standard error $\sigma_{R^{*}}=0.004$.

As in Neumeyer and Perri (2005), we assume that the de-trended country spread component $\widehat{D}_{t}$ depends on future expected total factor productivity. In other words, with a higher future expected total factor productivity, the repayment capacity of borrowers increases, which causes a reduction in the country spread risk. Therefore $\widehat{D}_{t}$ contains two components - an idiosyncratic risk component $\left(u_{t}\right)$ and second a term that depends upon the expected future total factor productivity, i.e.,

$$
\begin{aligned}
\widehat{D}_{t}= & -\eta E_{t} \widehat{A}_{t+1}+u_{t} \\
& u_{t} \text { is a random shock } \\
\eta= & 0.4425
\end{aligned}
$$

with a standard error of regression $\sigma_{U}=0.006$. We find that the above relation between

\footnotetext{
${ }^{32}$ The real interest rate is calculated as the lending rate adjusted for inflation using the GDP deflator. See http://data.worldbank.org/indicator/FR.INR.RINR. These lending rates are rates at which short and medium term financing needs of the private sector are met. These lending rates are differentiated according to the credit-worthiness of borrowers.

${ }^{33}$ Neumeyer and Perri (2005) and Tiryaki assume 91-day US Treasury bill rate. Ghate et. al (2013) also report the second order moments for India using a 91-day Treasury bill rate.
} 
country spreads and expected TFP is statistically significant. ${ }^{34}$ This means, a higher expected total factor productivity in time period $t+1$ indeed lowers is the country spread in time period $t$. We assume that all shocks are uncorrelated.

\subsection{Single Period Shocks}

There are three shocks in our model - TFP shocks $\left(\widehat{A}_{t}\right)$, world interest rate shocks $\left(\widehat{R}_{t}^{*}\right)$, and shocks to the country spread risk $\left(u_{t}\right)$. Since from equation $(30)$

$$
\widehat{R}_{t}^{P}=\widehat{R}_{t}^{*}+\widehat{D}_{t}
$$

a TFP shock will lower $\widehat{R}_{t}^{P}$ through a reduction in $D$.

We will analyze the effect of single period shocks on $\widetilde{y}_{t}, \widetilde{c}_{t}, \widetilde{x}_{t}, \widetilde{G}_{t}, \widetilde{l}_{t}$, and net exports, $\widetilde{n x}_{t} \cdot{ }^{35}$ We will see how a single period $10 \%$ shock affects the deviations of these variables from their corresponding steady state values. In particular, for any variable $z$, we define variable $l z$ as the deviation of the variable $z$ from it's steady state value of $\bar{z}$ i.e.,

$$
l z=z_{t}-\bar{z}
$$

\subsubsection{TFP shock}

Figure (6) plots the impulse response functions due to a single period shock in total factor productivity $(A)$.

\section{[INSERT FIGURE (6)]}

A one period positive total factor productivity shock, instantaneously causes output to increase. As a result, the deviation of output from its corresponding steady state value $(l y)$ increases. This is because an increase in the firm's productivity causes an increase in labor demand and demand for private capital. An increase in the demand for private capital

\footnotetext{
${ }^{34}$ In Neumeyer and Perri (2005), this model is called the induced country risk case. They also estimate another case, the independent country risk case, where, $\widehat{D}_{t}$, is assumed evolve according to an exogenous process. This exogenous process is assumed to follow an $\operatorname{AR}(1)$ process. However, an $\operatorname{AR}(1)$ fit for $\widehat{D}_{t}$ in our model was not statistically significant given our choice of the interest rate series. We therefore report all our calibration results only for the induced country risk case. As an alternative exogenous process, we assume

$$
\widehat{D}_{t}=\varepsilon_{t D}
$$

results for which are available on request.

${ }^{35}$ We have chosen the value of $\tau_{k}=\tau_{w}=\tau=0.01$ for generating the impulse responses in this section. While the impulse responses are on net exports, our calibrated second order moments are on net export to output ratio. This is similar to Neumeyer and Perri (2005), Ghate et al. (2013), and Tiryaki (2012).
} 
causes an increase in private investments $(l x)$. While an increase in the firm's demand for labor causes an increase in equilibrium labor $(l l)$ on impact and raises output, the positive income effect causes consumption $(l c)$ to also increase in comparison to it's steady state value. Government consumption $(l g)$ also increases on impact first due to a positive TFP shock. This is because an increase in output raises total tax revenue. $R_{t}^{P}$ (shown as $R$ in figure (6)) falls due to a reduction in the country spread risk. This occurs with a lag. Therefore interest incomes accruing to the government in time period $t+1$ falls. This causes a drop in $l g$ in $t+1$, and thereafter, converges very slowly to the steady state from above. This is because $\widehat{A}$ is more persistent than $\widehat{R}^{P},|\eta|<1$, and $l c$ does not converge to the steady state even after 40 quarters. The savings-investment (S-I) gap (shown as si_gp) falls on impact because savings decrease and investment $(l x)$ increases. The public revenue-expenditure gap (shown as $t r \_g p$ ) increases in time period $t+1$ because

$$
T R_{t}-G_{t}=-\left\{\left[R_{t-1}^{G}-1\right] \theta_{G}\right\} w_{t} l_{t}
$$

This is because $t r \_g p$ in time period $t$ depends on the interest rates of time period $t-1$ which falls because of a TFP shock. An instantaneous drop in net exports $(\ln x)$ therefore occurs due to a fall in the savings-investment gap. Net exports thereafter quickly converges to the corresponding steady state value because the public revenue-expenditure gap increases in $t+1$.

\subsubsection{Interest rate shock}

Figure (7) shows the impact of a single period shock to the world interest rate $R^{*}$. The domestic interest rate $(R)$ increases which causes an instantaneous drop in private consumption (lc) due to the inter-temporal substitution effect.

\section{[INSERT FIGURE (7)]}

Therefore, equilibrium labor $(l l)$ increases on impact due to a reduction in $(l c)$. Output in time period $t$ depends on $l_{t}$ and $k_{t-1}$. Since $k_{t-1}$ in time period $t$ is given from time period $t-1, l y$ increases on impact due to an increase in $l l$. Government consumption $(l g)$ drops in time period $t$ before it increases above the steady state level in $t+1$. This is because an initial reduction in tax revenue from lower consumption levels dominates the increase in tax revenue from the wage and rental income taxation. ${ }^{36}$ A positive interest rate shock causes

\footnotetext{
${ }^{36}$ Clearly, the initial rise or fall in $l g$ depends on the choice of fiscal policy parameters. As we discussed above, our choice of $\tau_{c}>\tau_{w}=\tau_{k}$ also puts higher weightage on the tax on consumption in comparison to tax on wage and capital income.
} 
government consumption $l g$ to then jump above the steady state in time period $t+1$ before it starts converging to the steady state from levels below zero. A combination of opposite movements in $l c$ and $l g$ causes $l l$ to finally converge to zero. Investments $(l x)$ falls because the private rate of return $(l r)$ increases through the no arbitrage condition. An increase in savings due to postponement of consumption and reduction in investments causes the savings-investment gap (shown as $s i \_g p$ ) to increase on impact. The government revenue to expenditure gap denoted by $t r \_g p$ (see (33)) falls because labor $(l l)$ increases. An increase in the savings-investment gap and a reduction in $t r \_g p$ therefore makes $\ln x$ increase on impact as shown in FIGURE (7).

The impact of a single period shock to idiosyncratic risk $(u)$ is shown in figure (8).

\section{[INSERT FIGURE (8)]}

The intuition for a single period shock to $u$ is identical to a single period shock to the world interest rate $R^{*}$ at time period $t$. The impulse responses however seem to be converging to the steady state very quickly since $u$ is random and not persistent.

\subsection{Multi-period Shocks}

Next, we calibrate our model with multi-period uncorrelated shocks to TFP $\left(\widehat{A}_{t}\right)$, world interest rates $\left(\widehat{R}_{t}^{*}\right)$ and idiosyncratic shocks to the country spread $\left(\widehat{u}_{t}\right)$ and compare the second order moments of our simulated data with the Indian quarterly data from 1999 Q2 to 2010 Q2. ${ }^{37}$ Table (4) summarizes our calibration results. We calibrate the model in stages to assess goodness of fit. First, we estimate the second order moments of our model when there is no fiscal policy in the baseline model. The results from estimating this model are reported in the column "No Fiscal Policy". In this case, the fiscal policy wedge, $\Gamma_{t}=\bar{\Gamma}=1$. Second, we include only government consumption $\widetilde{G}_{t}$ financed by factor income taxes. The results from estimating this model are reported in the column "Only G". Third, we assume that in addition to $\widetilde{G}_{t}$ the government also subsidizes working capital loans, where $R_{t}^{G}=R_{t}^{P}(1-s)$, to firms on the fraction, $\theta_{G} w_{t} l_{t}$, of their wage payments. We report results obtained by estimating this model in the column "G and S". The column "G and S (with high $\Theta$ )" reports results for a high value of $\Theta=75$. Finally, the column "Actual Data" reports the actual second order moments of the Indian data from Ghate et al. (2013).

\footnotetext{
${ }^{37}$ See table (5) in Ghate et. al (2013) for the Indian data. The simulated series estimated by the model was generated for 500 time periods and was then hp-filtered with the value of the multiplier chosen to be 1600 , a standard value used to hp-filter quarterly data.
} 
Table 4 : Comparison between the model and the data ${ }^{38}$

\begin{tabular}{lccccc}
\hline \hline Moments & No Fiscal Policy & Only G & G and S & G and S (with high $\Theta$ ) & Actual Data \\
\hline \hline$(1)$ & $(2)$ & $(3)$ & $(4)$ & $(5)$ & $(6)$ \\
\hline$\rho(C, Y)$ & 0.6033 & 0.4586 & 0.5126 & 0.5045 & 0.51 \\
$\rho(X, Y)$ & 0.1330 & 0.1022 & 0.1103 & 0.0247 & 0.69 \\
$\rho(R, Y)$ & -0.0832 & -0.0458 & -0.0546 & 0.0754 & 0.38 \\
$\rho\left(\frac{N X}{Y}, Y\right)$ & 0.1912 & 0.2562 & -0.1505 & -0.1792 & -0.15 \\
$\rho(G, Y)$ & - & 0.6882 & -0.32 & -0.0229 & -0.35 \\
& & & & & \\
$\sigma(C) / \sigma(Y)$ & 0.3548 & 0.3236 & 1.20 & 1.69 & 1.31 \\
$\sigma(X) / \sigma(Y)$ & 10.9 & 10.11 & 10.23 & 7.23 & 3.43 \\
$\sigma(R) / \sigma(Y)$ & 0.48 & 0.439 & 0.44 & 0.28 & 1.77 \\
$\sigma(N X) / \sigma(Y)$ & 11.13 & 10.57 & 10.64 & 7.82 & 1.04 \\
$\sigma(G) / \sigma(Y)$ & - & 0.358 & 1.55 & 0.23 & 5.53 \\
\hline \hline
\end{tabular}

\subsubsection{No fiscal policy}

In this case, the fiscal policy wedge, $\Gamma_{t}=\bar{\Gamma}=1$. This is because: $\tau_{k}=\tau_{w}=\tau_{c}=0, s=0$, and $\theta_{G}=\Theta=0$. The labor demand equation (26) becomes

$$
l_{t}^{D}=\left[\frac{(1-\alpha) A_{t}}{\widetilde{w}_{t}\left[(1-\theta)+\theta R_{t-1}^{P}\right]}\right]^{\frac{1}{\alpha}} \frac{\widetilde{k}_{t-1}}{(1+\gamma)} .
$$

Unlike in (26), in (34) the effect of a positive shock to $R_{t}^{P}$ on labor demand is fully transmitted through the labor market by lowering labor demand. The labor supply equation (24), becomes the standard labor supply equation in the absence of fiscal policy:

$$
l_{t}^{S}=1-\frac{\widetilde{c}_{t}}{\widetilde{w}_{t}}\left(\frac{1-\mu}{\mu}\right)
$$

As shown in column 2 in Table 4, we observe that consumption, investment, and the netexport to output ratio are pro-cyclical, whereas real interest rates are weakly counter-cyclical. While this model under-estimates the relative volatility of consumption and the real interest rate, it over-estimates the relative volatility of investment and the net-export to output ratio.

\footnotetext{
${ }^{38} \rho(Z, Y)$ is the correlation coefficient of variable $Z$ with output $Y . \sigma(Z) / \sigma(Y)$ is the relative standard deviation of variable $Z$ with output $Y$. Also, refer to table (2) for second order moments of the Indian data.
} 


\subsubsection{Government consumption}

Suppose that the government imposes factor income taxes and spends it only on government consumption that affects utility. The government, however, does not subsidize working capital loans. Under this specification,

$$
\begin{aligned}
\tau_{k} & =\tau_{w}=\tau>0, \tau_{c}>0 \\
s & =\theta_{G}=0 \\
\Theta & >0 .
\end{aligned}
$$

Labor supply in (24) is now given by

$$
l_{t}^{S}=1-\frac{\widetilde{c}_{t}}{\widetilde{w}_{t}}\left(\frac{1-\mu}{\mu}\right) \Gamma_{t}^{\prime}
$$

The fiscal policy wedge, in this case, $\Gamma_{t}^{\prime}$, is given by

$$
\Gamma_{t}^{\prime}=\left(\frac{1+\tau_{c}}{1-\tau_{w}}\right) \frac{\Psi_{t}^{\prime}}{D_{t-1}^{\prime}}
$$

such that

$$
\begin{aligned}
D_{t-1}^{\prime} & =1+\Theta \tau_{w}\left(\frac{1-\mu}{\mu}\right)\left(\frac{1+\tau_{c}}{1-\tau_{w}}\right)>1 \text { and } \\
\Psi_{t}^{\prime} & =\left[1+\Theta \tau_{c}+\frac{\Theta \tau_{k} r_{t} \widetilde{k}_{t-1}}{(1+\gamma) \widetilde{c}_{t}}+\frac{\Theta \tau_{w} \widetilde{w}_{t}}{\widetilde{c}_{t}}\right]>1 .
\end{aligned}
$$

As shown in column 3 government consumption is quite strongly pro-cyclical. This is expected because government expenditure given by

$$
\widetilde{G}_{t}=\tau_{c} \widetilde{c}_{t}++\tau_{w} \widetilde{w}_{t} l_{t}+\tau_{k} r_{t} \frac{\widetilde{k}_{t-1}}{(1+\gamma)}
$$

which is a fraction of private income. Therefore any change in consumption and income directly affects government consumption. It is, however, estimated to be less volatile than output which is at odds with the actual data.

In this model real interest rates are even less counter-cyclical compared to the "No Fiscal Policy" case in column 2, and investment is less pro-cyclical. A positive interest rate shock does not have a direct effect on the fiscal policy wedge, although it does affect the wedge, and therefore $l_{t}^{S}$, indirectly through other endogenous variable such as $\widetilde{c}_{t}, r_{t}, \widetilde{k}_{t}$, and $\widetilde{w}_{t}$. In 
particular, a positive interest rate shock always increases the fiscal policy wedge, which tends to offset the outward movements in labor supply due to a reduction in consumption. Interest rates therefore tend to become less counter-cyclical.

The important difference however, is that the relative volatility of consumption, investments, and net exports have all fallen compared to the model with no fiscal policy. This suggests that $\widetilde{G}_{t}$ has a stabilizing effect. Consumption becomes less volatile because on the one hand households have to pay factor income taxes while on the other, a reduction in consumption due to taxes are returned to the agents through $\widetilde{G}_{t}$ which is more volatile than consumption.

Including $\widetilde{G}_{t}$ also makes the net-exports to output ratio more pro-cyclical. We can rewrite the net exports-to-output ratio as,

$$
n x_{t}=\frac{\left(s_{t}-x_{t}\right)+\left(T R_{t}-G_{t}\right)}{y_{t}}
$$

where $s$ is savings and $x$ is investments. Since in every time period,

$$
T R_{t}=G_{t}
$$

we get

$$
n x_{t}=\frac{s_{t}-x_{t}}{y_{t}}
$$

Since investments are weakly pro-cyclical with output, the cyclicality of savings with output dominates. Therefore the net-exports to output ratio will be pro-cyclical.

\subsubsection{Government consumption and subsidy}

Now suppose

$$
\begin{aligned}
\tau_{k} & =\tau_{w}=\tau>0, \tau_{c}>0 \\
s & >0, \theta_{G}>0 \\
\Theta & >0 .
\end{aligned}
$$

This is our model as discussed in Section 2 in which labor supply is now given by (24) and labor demand is given by (26). The moments are summarized in column 4 of Table 4 . In contrast to the model with only government consumption, we now get counter-cyclical government consumption, counter-cyclical net-exports to output ratio, pro-cyclical consumption 
and investments, and weakly counter-cyclical real interest rates. ${ }^{39}$ Our model qualitatively replicates the standard stylized facts that motivate the theoretical framework of Neumeyer and Perri (2005) through an alternate but compatible mechanism.

We find that contemporaneous correlation of consumption, the net exports-to-output ratio, and government expenditure with respect to output are very close to the Indian data. While private investments are less pro-cyclical as compared to the data (which is due to a highly over-estimated investment volatility), interest rates continue to be weakly countercyclical. Relative volatility of consumption, investments, net exports, and government expenditures are all closer to the Indian data and higher in the presence of subsidies to the working capital loans to firms.

Government expenditures are now significantly counter-cyclical due to high subsidies given to firms. The net-exports to output ratio, given by

$$
n x_{t}=\frac{\left(s_{t}-x_{t}\right)+\left(T R_{t}-G_{t}\right)}{y_{t}},
$$

are counter-cyclical because of a falling savings-investment gap and a negative public revenueexpenditures gap. Finally, strong income effects from TFP on consumption and the dampening effect of subsidies on the labor, and therefore output, increases the relative volatility of consumption with respect to output.

While the model with all three shocks and both roles for fiscal policy qualitatively match the stylized facts of EMEs, we find so far that the calibrated moments of this variant of the model (full fiscal policy) are also closer to the Indian data than columns 2 and 3. However, while predicted relative consumption volatility is approximately close to the Indian data, relative volatility of government consumption is under estimated and that of investment and net exports are over estimated. We also find that contemporaneous correlations of investment and real interest rates are much less as compared to the actual Indian data.

\subsubsection{Government consumption and subsidy (under high $\Theta$ )}

In our model, fiscal policy affects the economy by distorting the labor market equilibrium. On the one hand, a subsidy from the government affects the labor demand, whereas on the other, the utility enhancing government, which imposes a time-varying fiscal policy wedge, affects labor supply by influencing not just its inward-outward movements, but also its slope. As a result, fiscal policy affects the transmission of the interest rate shocks on the labor market, and therefore affects the fluctuations in other endogenous variables such as output,

\footnotetext{
${ }^{39}$ In our section on counter-factuals, we discuss the effect of $\Theta$ and $\theta_{G}$ on the cyclical properties of interest rates, government expenditure, and the net exports-output ratio.
} 
consumption, and net exports. In this section, we therefore analyze the effect of changes in $\Theta$ on some of our calibration results.

In our simulations for arbitrary values of $\Theta=\{0.5,5,75\}$, we obtain the following observations. ${ }^{40}$ While government expenditures are relatively unimportant in comparison to private consumption for $\Theta<1$, an increase in $\Theta$ makes government consumption more important for the agent. Hence, an increase in $\Theta$ makes consumption more volatile, as can be seen in Column 5 of Table 4 . The higher volatility causes a reduction in the contemporaneous correlation between private consumption and output. In particular, when $\Theta<1$, private consumption is less volatile compared to output, which is not true for our sample of EMEs. Our model suggests that a higher $\Theta$ generates this higher consumption volatility.

As can be seen from Column 5, for very high values of $\Theta, \rho(R, Y)>0$, i.e., real interest rates, from being counter-cyclical, become pro-cyclical. As $\Theta$ increases, private consumption becomes more volatile. As a result, a positive interest rate shock causes a bigger reduction in current consumption. A big reduction in current consumption dominates the dampening effect of an increase in $\Gamma$ on labor supply. The net effect is that equilibrium labor increases by more due to a positive interest rate shock. The real interest rate is however only mildly pro-cyclical because the productivity shock has also exerted a simultaneous contemporaneous positive income effect.

Government expenditures also become weakly counter-cyclical (with a higher $\Theta$ ) - as in Column 5 - which therefore makes the net exports-to-output ratio marginally more countercyclical. From equation (7), we know that government expenditure is financed by taxing consumption, income, and a net interest income from lending to firms. As $\Theta$ increases, with a positive interest rate shock, on the one hand, an increase in income and an increase in the interest rate increases revenue generated from wage, capital, and interest incomes. This makes government expenditures less counter-cyclical with a progression towards becoming pro-cyclical. On the other hand, a big reduction in consumption due to an interest rate shock causes a reduction in revenue from taxing consumption. This makes government expenditures fall for an increase in output, thereby making it counter-cyclical. Since taxing consumption is a bigger revenue source for the government, the net effect is that increases in revenue from taxing incomes is dampened by reductions in revenue from consumption. This makes government expenditures weakly counter-cyclical or almost a-cyclical. Being a residual, the net-export-to-output ratio becomes marginally more counter-cyclical.

\footnotetext{
${ }^{40}$ These results are available from the authors on request.
} 


\section{The Role of Fiscal Policy as an Automatic Stabilizer}

Our model outlines how fiscal policy can play the role of an automatic stabilizer when an economy is hit with interest rate shock which adversely affects labor market outcomes and also real output. Since government expenditure in our model is non-discretionary, it adjusts automatically with other endogenous variables. Table 4 shows how fiscal policy dampens overall volatility in the economy, but leads to a trade-off. A rise in $\Theta$ results in pro-cyclical interest rates and lesser relative volatility for $X, R, N X$, and $G$, even though these outcomes obtain at the expense of higher consumption volatility (see Column 5). ${ }^{41}$ Higher consumption volatility happens because of a strong inter-temporal substitution effect driven by the private and public components of consumption beings perfect substitutes and $\Theta$ is high. This makes private consumption's response to a positive interest rate shock high. A higher $\tau_{c}$ would also make private consumption's response to a positive interest rate shock high making interest rates more pro-cyclical.

Table 4 also identifies the intuition behind why government spending volatility goes down. This happens because as long as $\tau_{c}$ is sufficiently large, a positive interest rate shock reduces $\tau_{c} \widetilde{c}_{t}$, which also reduces $\widetilde{G}_{t}$. A reduction in $\widetilde{c}_{t}$ leads to an increase in labor supply and output. Thus $\widetilde{y}_{t}$ increases and $\widetilde{G}_{t}$ falls. A rise in $\Theta$ causes a bigger increase in $\widetilde{l}_{t}$ which makes $\widetilde{y}_{t}$ more volatile. This causes a reduction in the relative volatility of $\widetilde{G}_{t}$.

As discussed in the previous section, since the impact of the fiscal policy wedge $\left(\frac{\partial \Gamma_{t}}{\partial R_{t-1}^{P}}\right)$ is increasing in $\Theta$, a higher value of $\Theta$ reduces labor supply more when $\Theta$ is higher. However, a higher $\Theta$ also leads to a larger reduction in private consumption, $\widetilde{c}_{t}$, and this inter-temporal substitution effect leads to an increase in labor supply which off-sets the reduction in labor supply from the fiscal policy wedge. The net effect on labor supply is therefore positive. Therefore the strength of substitutability between, $\widetilde{c}_{t}$, and $\widetilde{G}_{t}$, captured by $\Theta$ is crucial for fiscal policy's role as an automatic stabilizer.

\section{Conclusion}

We build a tractable small open economy RBC model in which fiscal policy has a role in making pro-cyclical real interest rates consistent with counter-cyclical net exports and higher consumption volatility. Our theoretical model contributes to the growing literature on fiscal policy in small open economies. In particular, we show that by adding a role for fiscal policy in the Neumeyer and Perri (2005) setup, we are able to establish a causal link between

\footnotetext{
${ }^{41}$ While we do not assess welfare in the model, Gali (1994) shows that large taxes and large government expenditures - while stabilizing in nature - have welfare reducing effects.
} 
the nature of fiscal policy (counter-cyclical / a-cyclical), real interest rates (pro-cyclical / counter-cyclical), counter-cyclical net exports, and higher relative consumption volatility. Our framework therefore can be seen as a more general framework to understand the effect of interest rate shocks on the real economy discussed in the empirical business cycle literature. We then calibrate the model to India to qualitatively match its business cycle properties. We also discuss the role that fiscal policy as an automatic stabilizer in the context of our model.

From a policy standpoint, our model suggests how the adverse effects of interest rate shocks on labor market outcomes can be mitigated by fiscal policy. For future work, we hope to introduce sovereign debt and endogenize country spreads with sovereign default risks. We also hope to undertake a welfare analysis of various types of fiscal policy in our model. 


\section{References}

[1] Agénor, Pierre-Richard., McDermott, C.John, and Prasad, Eswar S., "Macroeconomic fluctuations in developing countries: some stylized facts", World Bank Economic Review (14) (2000), pp. 251-285

[2] Aguiar, Mark., and Gopinath, Gita, "Emerging market business cycles: The cycle is the trend", Journal of Political Economy (115)(1) (2007); pp 69-102

[3] Ambler, Steve, and Paquet, Alain, "Fiscal spending shocks, endogenous government spending, and real business cycles" Journal of Economic Dynamics and Control (20) (1-3) (1996); pp 237-256

[4] Barro, Robert J., "Output effects of government purchases" Journal of Political Economy (89) (1981); pp 1086-1121

[5] Bhattacharya, Rudrani, Patnaik, Ila, and Pundit, Madhavi, "Emerging economy business cycles: Financial integration and terms of trade shocks", Working paper No. 2013/120, National Institute of Public Finance and Policy (2013).

[6] CEIC Indian Premium Database (2012), http://www.ceicdata.com/en/countries/india

[7] Christiano, Lawrence J., and Eichenbaum, Martin, "Current real business cycle theories and aggregate labor market fluctuations" American Economic Review (82) (1992); pp. $430-450$

[8] Cuadra, Gabriel, Sanchez, Juan, and Sapriza, Horacio,"Fiscal Policy and Default Risk in Emerging Markets," Review of Economic Dynamics (13)(2) (2010); pp. 452-469

[9] Frankel, Jeffrey A., Vegh, Carlos A., and Vuletin Guillermo, "On graduation from fiscal procyclicality" Journal of Development Economics (100) (2013); pp. 32-47

[10] Gali, Jordi "Government size and macroeconomic stability" European Economic Review (38) (1994); pp. 117-132

[11] Ghate, Chetan, Pandey, Radhika and Patnaik, Ila, "Has Indian emerged? Business cycle stylized facts from a transitioning economy" Structural Change and Economic Dynamics (24) (2013); pp. 157-172

[12] Ghate, Chetan, Glomm, Gerhard and Liu, Jialu, "Sector infrastructure investment in an unbalanced growing economy: The case of India" working paper (2012) 
[13] Greenwood, Jeremy, Hercowitz, Zvi, and Huffman, Gregory W., "Investment, capacity utilization, and the real business cycle" American Economic Review (78)(3) (1988); pp. $402-417$

[14] Handbook of Statistics of the Indian Economy, Reserve Bank of India (2012)

[15] Kuehlwein, Michael, "Evidence on the substitutability between government purchases and consumer spending within specific spending categories" Economics Letters (58) (1998); pp. 325-329

[16] Lane, Philip R., "The cyclical behaviour of fiscal policy: evidence from the OECD" Journal of Public Economics (87) (2003); pp. 2661-2675

[17] Li, Nan, "Cyclical wage movements in emerging markets compared to developed economics: The role of interest rates" Review of Economic Dynamics (14) (2011); pp. 686-704

[18] Loayza, N., Ranciére, R., Servén, L., and Ventura, J., "Macroeconomic volatility and welfare in developing countries: An introduction" The World Bank Economic Review (21)(3) (2007); pp. 343-357

[19] Male, Rachel, "Developing country business cycles: Revisiting the stylized facts", Working paper no. 664, School of Economics and Finance, Queen Mary University of London (2010)

[20] Neumeyer, P.A., and Perri, F., "Business cycles in emerging economies: The role if interest rates" Journal of Monetary economics (52) (2005); pp. 345-380

[21] Ni, Shawn, "An empirical analysis on the substitutability between private consumption and government purchases" Journal of Monetary economics (36) (1995); pp. 593-605

[22] Penn World Tables Version 8.0, http://www.rug.nl/research/ggdc/data/penn-worldtable (2014)

[23] Poirson, Héléne, "The Tax System in India: Could Reform Spur Growth?" IMF Working Paper WP/06/93 (2006)

[24] Prescott, Edward C., "Prosperity and Depression: 2002 Richard T. Ely Lecture," Working Papers 618, Federal Reserve Bank of Minneapolis (2002)

[25] Rand, J., and Tarp, F., "Business cycles in developing countries: Are they different?" World Development (30)(12) (2002), pp. 2071-2088 
[26] Reuters India database, http://in.reuters.com/article/2013/06/10/india-plridINL3N0EM1YU20130610?type=companyNews

[27] Roche, Maurice J., "Government spending and the international business cycle" Canadian Journal of Economics (29)(4) (1996); pp. 865-884

[28] Talvi, Ernesto, and Vegh, Carlos. A, "Tax Base Variability and Procyclicality of Fiscal Policy" Journal of Development Economics (78)(1) (2005); pp. 156-190

[29] Tiryaki, S. Tolga, "Interest rates and real business cycles in emerging markets" The B.E. Journal of Macroeconomics (11) (1) (2011), (Topics), Article 41

[30] Uribe, Martin, and Yue, Vivian Z., "Country spreads and emerging economies: Who drives whom?" Journal of International Economics (69)(1) (2006); pp. 6-36

[31] World Bank Database, http://data.worldbank.org/indicator/FR.INR.RINR (2012)

[32] World Bank Database, http://data.worldbank.org/indicator/NE.CON.GOVT.ZS (2013) 


\section{Technical Appendix}

\section{Steady state calculations}

The following are the set of steady state conditions that will be used in the model

$$
\begin{gathered}
\bar{R}^{P}=\frac{(1+\gamma)}{\widetilde{\beta}} \\
\bar{r}=\frac{\bar{R}-(1-\delta)}{\left(1-\tau_{k}\right)}
\end{gathered}
$$

From the firm's FOC,

$$
\bar{y}=\frac{\bar{r} \bar{k}}{(1+\gamma) \alpha}
$$

and

$$
(1-\alpha) \bar{y}=\bar{w} \bar{l}\left[(1-\theta)+\bar{R}^{P}\left(\theta-s \theta_{G}\right)\right]
$$

From (21) we got

$$
(1-\bar{l})=\frac{(1-\mu)}{\mu} \frac{\left(1+\tau_{c}\right)}{\left(1-\tau_{w}\right)} \frac{\bar{c}+\Theta \bar{G}}{\bar{w}} .
$$

This implies

$$
\begin{aligned}
\frac{(1-\bar{l})}{\bar{l}} & =\frac{(1-\mu)}{\mu} \frac{\left(1+\tau_{c}\right)}{\left(1-\tau_{w}\right)} \frac{\frac{\bar{c}}{\bar{y}}+\Theta \frac{\bar{G}}{\bar{y}}}{\frac{\bar{w} \bar{l}}{\bar{y}}} . \\
& \Rightarrow \bar{l}=\frac{1}{\left[1+\frac{(1-\mu)}{\mu} \frac{\left(1+\tau_{c}\right)}{\left(1-\tau_{w}\right)} \frac{\overline{\bar{y}}+\Theta \frac{\bar{G}}{\bar{y}}}{\frac{\bar{w} \bar{l}}{\bar{y}}}\right]} .
\end{aligned}
$$

From the output technology we know

$$
\widetilde{y}_{t}=\frac{A_{t}}{(1+\gamma)^{\alpha}}\left[\widetilde{k}_{t-1}\right]^{\alpha} l_{t}^{1-\alpha}
$$

This implies, at steady state,

$$
\bar{y}=\frac{\bar{A}}{(1+\gamma)^{\alpha}} \bar{k}^{\alpha} \bar{l}^{1-\alpha} .
$$

We also know from (39)

$$
\bar{y}=\frac{\bar{r} \bar{k}}{(1+\gamma) \alpha} .
$$


This implies

$$
\begin{aligned}
& \frac{\bar{r} \bar{k}}{(1+\gamma) \alpha}=\frac{\bar{A}}{(1+\gamma)^{\alpha}} \bar{k}^{\alpha} \bar{l}^{1-\alpha} \\
& \Rightarrow \frac{\bar{r} \bar{k}^{1-\alpha}}{(1+\gamma) \alpha} \frac{(1+\gamma)^{\alpha}}{\bar{A}}=\bar{l}^{1-\alpha} \\
& \Rightarrow \bar{k}=\left[\frac{\bar{A} \alpha}{\bar{r}}\right]^{\frac{1}{1-\alpha}}(1+\gamma) \bar{l}
\end{aligned}
$$

This implies from (41)

$$
\bar{w}=\frac{(1-\alpha) \bar{y}}{\left[(1-\theta)+\bar{R}^{P}\left(\theta-s \theta_{G}\right)\right] \bar{l}} .
$$

The expressions of $\bar{k}, \bar{y}, \bar{w}, \bar{l}$, and $\bar{r}$ will follow. Once $\bar{y}$ is known,

$$
\bar{b}=\left(\frac{b}{y}\right) \bar{y}
$$

where, $\left(\frac{b}{y}\right)$ is a known parameter. From the budget constraint

$$
\frac{\bar{c}}{\bar{y}}=\frac{\left(1-\tau_{w}\right) \frac{\bar{w} \bar{l}}{\bar{y}}}{\left(1+\tau_{c}\right)}+\frac{\left(1-\tau_{k}\right) \frac{\bar{r} \bar{k}}{\bar{y}}}{\left(1+\tau_{c}\right)(1+\gamma)}+\frac{\frac{\bar{R}^{P} \bar{b}}{\bar{y}}}{\left(1+\tau_{c}\right)(1+\gamma)}-\frac{\frac{\bar{k}}{\bar{y}}}{\left(1+\tau_{c}\right)}+\frac{(1-\delta) \frac{\bar{k}}{\bar{y}}}{(1+\gamma)\left(1+\tau_{c}\right)}-\frac{\frac{\bar{b}}{\bar{y}}}{\left(1+\tau_{c}\right)} .
$$

From the government budget constraint

$$
\frac{\bar{G}}{\bar{y}}=\left[\tau_{c} \frac{\bar{c}}{\bar{y}}+\left\{\left[\bar{R}^{P}(1-s)-1\right] \theta_{G}+\tau_{w}\right\} \frac{\bar{w} \bar{l}}{\bar{y}}+\frac{\tau_{k}}{(1+\gamma)} \frac{\bar{r} \bar{k}}{\bar{y}}\right]
$$

This implies

$$
\begin{aligned}
& \frac{\bar{c}}{\bar{y}}+\Theta \frac{\bar{G}}{\bar{y}}=\frac{\bar{w} \bar{l}}{\bar{y}}\left[\frac{\left(1-\tau_{w}\right)\left(1+\Theta \tau_{c}\right)}{\left(1+\tau_{c}\right)}+\Theta\left\{\left[\bar{R}^{P}(1-s)-1\right] \theta_{G}+\tau_{w}\right\}\right] \\
&+\frac{\bar{r} \bar{y}}{\bar{y}(1+\gamma)}\left[\frac{\left(1-\tau_{k}\right)\left(1+\Theta \tau_{c}\right)}{\left(1+\tau_{c}\right)}+\Theta \tau_{k}\right] \\
&+\frac{\bar{b}\left(1+\Theta \tau_{c}\right)}{\bar{y}\left(1+\tau_{c}\right)}\left[\frac{\bar{R} P}{(1+\gamma)}-1\right]-\frac{\bar{k}\left(1+\Theta \tau_{c}\right)}{\bar{y}\left(1+\tau_{c}\right)}\left[\frac{\gamma+\delta}{(1+\gamma)}\right]
\end{aligned}
$$


This can be further simplified

$$
\begin{aligned}
\frac{\bar{c}}{\bar{y}}+\Theta \frac{\bar{G}}{\bar{y}}= & \frac{(1-\alpha)}{\left[(1-\theta)+\bar{R}^{P}\left(\theta-s \theta_{G}\right)\right]}\left[\frac{\left(1-\tau_{w}\right)\left(1+\Theta \tau_{c}\right)}{\left(1+\tau_{c}\right)}+\Theta\left\{\left[\bar{R}^{P}(1-s)-1\right] \theta_{G}+\tau_{w}\right\}\right] \\
& +\alpha\left[\frac{\left(1-\tau_{k}\right)\left(1+\Theta \tau_{c}\right)+\left(1+\tau_{c}\right) \Theta \tau_{k}}{\left(1+\tau_{c}\right)}\right] \\
& +\frac{\left(1+\Theta \tau_{c}\right)\left[\bar{R}^{P}-(1+\gamma)\right]}{\left(1+\tau_{c}\right)(1+\gamma)}\left[\frac{(1-\alpha) \theta}{\left[(1-\theta)+\bar{R}^{P}\left(\theta-s \theta_{G}\right)\right]}+\frac{\overline{N F A}}{\bar{y}}\right] \\
& -\frac{\left(1-\tau_{k}\right)(1+\gamma)\left(1+\Theta \tau_{c}\right) \alpha(\gamma+\delta)}{\left[\bar{R}^{P}-(1-\delta)\right]\left(1+\tau_{c}\right)(1+\gamma)} \\
= & \Upsilon \text {, say. }
\end{aligned}
$$

Hence

$$
\bar{l}=\frac{1}{\left[1+\frac{(1-\mu)}{\mu} \frac{\left(1+\tau_{c}\right)}{\left(1-\tau_{w}\right)} \frac{\left.\Upsilon[1-\theta)+\bar{R}^{P}\left(\theta-s \theta_{G}\right)\right]}{(1-\alpha)}\right]} .
$$

Therefore other parameters are estimated as

$$
\begin{aligned}
\overline{\bar{k}} & =\frac{\left(1-\tau_{k}\right)(1+\gamma) \alpha}{\bar{R}^{P}-(1-\delta)} \\
\frac{\bar{y} \bar{l}}{\bar{y}} & =\frac{(1-\alpha)}{\left[(1-\theta)+\bar{R}^{P}\left(\theta-s \theta_{G}\right)\right]} \\
\frac{\bar{r} \bar{k}}{\bar{y}} & =(1+\gamma) \alpha \\
\bar{r} & =\frac{\bar{R}^{P}-(1-\delta)}{\left(1-\tau_{k}\right)} \\
\bar{b} & =\left(\theta-\theta_{G}\right) \frac{(1-\alpha)}{\left[(1-\theta)+\bar{R}^{P}\left(\theta-s \theta_{G}\right)\right]}+\frac{\left(1-\tau_{w}\right)}{\bar{y} A} \\
\overline{\bar{y}} & \frac{(1-\alpha)}{\bar{c}} \\
\overline{\bar{y}} & =\left[(1-\theta)+\bar{R}^{P}\left(\theta-s \theta_{G}\right)\right]
\end{aligned}
$$




$$
\begin{gathered}
+\frac{\alpha\left(1-\tau_{k}\right)}{\left(1+\tau_{c}\right)}-\frac{\left(1-\tau_{k}\right)(\gamma+\delta) \alpha}{\left[\bar{R}^{P}-(1-\delta)\right]\left(1+\tau_{c}\right)} \\
+\frac{1}{\left(1+\tau_{c}\right)}\left[\frac{\bar{R}^{P}}{(1+\gamma)}-1\right]\left[\frac{(1-\alpha) \theta}{\left[(1-\theta)+\bar{R}^{P}\left(\theta-s \theta_{G}\right)\right]}+\frac{\overline{N F A}}{\bar{y}}\right] \\
\frac{\bar{G}}{\bar{y}}=\left[\tau_{c} \frac{\bar{c}}{\bar{y}}+\left\{\left[\bar{R}^{P}(1-s)-1\right] \theta_{G}+\tau_{w}\right\} \frac{\bar{w} \bar{l}}{\bar{y}}+\frac{\tau_{k}}{(1+\gamma)} \frac{\bar{r} \bar{k}}{\bar{y}}\right], \text { follows. }
\end{gathered}
$$

Finally for net exports,

$$
\begin{aligned}
\widetilde{N X}_{t} & =\widetilde{y}_{t}-\widetilde{c}_{t}-\widetilde{x}_{t}-\widetilde{G}_{t} \\
& \Rightarrow \frac{\widetilde{N X}_{t}}{\widetilde{y}_{t}}=1-\frac{\widetilde{c}_{t}}{\widetilde{y}_{t}}-\frac{\widetilde{x}_{t}}{\widetilde{y}_{t}}-\frac{\widetilde{G}_{t}}{\widetilde{y}_{t}} \\
& \Rightarrow \widetilde{n x}_{t}=1-\frac{\widetilde{c}_{t}}{\widetilde{y}_{t}}-\frac{\widetilde{x}_{t}}{\widetilde{y}_{t}}-\frac{\widetilde{G}_{t}}{\widetilde{y}_{t}} \\
& \Rightarrow \overline{n x}=1-\frac{\bar{c}}{\bar{y}}-\frac{\bar{x}}{\bar{y}}-\frac{\bar{G}}{\bar{y}}, \text { clearly follows from above. }
\end{aligned}
$$

\section{Proposition (1)}

We know from the agents problem, labor supply is given by

$$
l_{t}^{S}=1-\left(\frac{1-\mu}{\mu}\right)\left(\frac{1+\tau_{c}}{1-\tau_{w}}\right)\left(\frac{\widetilde{c}_{t}^{*}}{\widetilde{w}_{t}}\right)
$$

which implies

$$
\begin{aligned}
l_{t}^{S} & =1-\left(\frac{1-\mu}{\mu}\right)\left(\frac{1+\tau_{c}}{1-\tau_{w}}\right)\left(\frac{\widetilde{c}_{t}+\Theta \widetilde{G}_{t}}{\widetilde{w}_{t}}\right) \\
& =1-\left(\frac{1-\mu}{\mu}\right)\left(\frac{1+\tau_{c}}{1-\tau_{w}}\right) \frac{\left\{\widetilde{c}_{t}+\Theta\left[\begin{array}{c}
\left.\left.+\left[\left\{R_{t-1}^{P}(1-s)-1\right\} \theta_{G}+\tau_{w}\right] \widetilde{w}_{t} l_{t}\right]\right\} \\
+\frac{\tau_{k} r_{t} \widetilde{c}_{t-1}}{1+\gamma}
\end{array}\right]\right.}{\widetilde{w}_{t}} \\
& =1-\left(\frac{1-\mu}{\mu}\right)\left(\frac{1+\tau_{c}}{1-\tau_{w}}\right) \frac{\left\{\left(1+\Theta \tau_{c}\right) \widetilde{c}_{t}+\Theta\left[\begin{array}{c}
\left\{\left[R_{t-1}^{P}(1-s)-1\right] \theta_{G}+\tau_{w}\right\} \widetilde{w}_{t} l_{t} \\
+\frac{\tau_{k} r_{t} \widetilde{k}_{t-1}}{1+\gamma}
\end{array}\right]\right\}}{\widetilde{w}_{t}}
\end{aligned}
$$


This implies

$$
\begin{aligned}
& l_{t}^{S}\left[1+\Theta\left(\frac{1-\mu}{\mu}\right)\left(\frac{1+\tau_{c}}{1-\tau_{w}}\right)\left\{\left[R_{t-1}^{P}(1-s)-1\right] \theta_{G}+\tau_{w}\right\}\right] \\
= & 1-\left(\frac{1-\mu}{\mu}\right)\left(\frac{1+\tau_{c}}{1-\tau_{w}}\right) \frac{\widetilde{c}_{t}}{\widetilde{w}_{t}}\left\{\left(1+\Theta \tau_{c}\right)+\frac{\Theta \tau_{k} r_{t} \widetilde{k}_{t-1}}{(1+\gamma) \widetilde{c}_{t}}\right\}
\end{aligned}
$$

Define

$$
D_{t-1}=\left[1+\Theta\left(\frac{1-\mu}{\mu}\right)\left(\frac{1+\tau_{c}}{1-\tau_{w}}\right)\left\{\left[R_{t-1}^{P}(1-s)-1\right] \theta_{G}+\tau_{w}\right\}\right] .
$$

Therefore,

$$
\begin{aligned}
& l_{t}^{S}=\frac{1}{D_{t-1}}-\frac{\widetilde{c}_{t}}{\widetilde{w}_{t}}\left(\frac{1-\mu}{\mu}\right)\left(\frac{1+\tau_{c}}{1-\tau_{w}}\right)\left[\frac{1+\Theta \tau_{c}}{D_{t-1}}+\frac{\Theta \tau_{k} r_{t} \widetilde{k}_{t-1}}{(1+\gamma) \widetilde{c}_{t} D_{t-1}}\right] \\
& =\frac{1+\Theta\left(\frac{1-\mu}{\mu}\right)\left(\frac{1+\tau_{c}}{1-\tau_{w}}\right)\left\{\left[R_{t-1}^{P}(1-s)-1\right] \theta_{G}+\tau_{w}\right\}}{D_{t-1}} \\
& -\frac{\widetilde{c}_{t}}{\widetilde{w}_{t}}\left(\frac{1-\mu}{\mu}\right)\left(\frac{1+\tau_{c}}{1-\tau_{w}}\right)\left[\frac{1+\Theta \tau_{c}}{D_{t-1}}+\frac{\Theta \tau_{k} r_{t} \widetilde{k}_{t-1}}{(1+\gamma) \widetilde{c}_{t} D_{t-1}}\right] \\
& -\frac{\Theta\left(\frac{1-\mu}{\mu}\right)\left(\frac{1+\tau_{c}}{1-\tau_{w}}\right)\left\{\left[R_{t-1}^{P}(1-s)-1\right] \theta_{G}+\tau_{w}\right\}}{D_{t-1}} \\
& \Rightarrow l_{t}^{S}=1-\frac{\widetilde{c}_{t}}{\widetilde{w}_{t}}\left(\frac{1-\mu}{\mu}\right)\left(\frac{1+\tau_{c}}{1-\tau_{w}}\right)\left[\frac{1+\Theta \tau_{c}}{D_{t-1}}+\frac{\Theta \tau_{k} r_{t} \widetilde{k}_{t-1}}{(1+\gamma) \widetilde{c}_{t} D_{t-1}}+\frac{\Theta\left\{\left[R_{t-1}^{P}(1-s)-1\right] \theta_{G}+\tau_{w}\right\} \widetilde{w}_{t}}{D_{t-1} \widetilde{c}_{t}}\right] \\
& \Rightarrow l_{t}^{S}=1-\frac{\widetilde{c}_{t}}{\widetilde{w}_{t}}\left(\frac{1-\mu}{\mu}\right)\left(\frac{1+\tau_{c}}{1-\tau_{w}}\right) \frac{\Psi_{t}}{D_{t-1}} \\
& \Rightarrow l_{t}^{S}=1-\frac{\widetilde{c}_{t}}{\widetilde{w}_{t}}\left(\frac{1-\mu}{\mu}\right) \Gamma_{t} .
\end{aligned}
$$

Let's now define

$$
\varrho_{t-1}=\left\{\left[R_{t-1}^{P}(1-s)-1\right] \theta_{G}+\tau_{w}\right\}>0 .
$$

We can therefore re-write $\Gamma_{t}$

$$
\Gamma_{t}=\left(\frac{1+\tau_{c}}{1-\tau_{w}}\right) \frac{\left[1+\Theta \tau_{c}+\frac{\Theta \tau_{k} r_{t} \widetilde{\widetilde{k}}_{t-1}}{(1+\gamma) \widetilde{c}_{t}}+\frac{\Theta \varrho_{t-1} \widetilde{w}_{t}}{\widetilde{c}_{t}}\right]}{\left[1+\Theta\left(\frac{1-\mu}{\mu}\right)\left(\frac{1+\tau_{c}}{1-\tau_{w}}\right) \varrho_{t-1}\right]} .
$$


Now, is

$$
\Gamma_{t}>1 ?
$$

This is true if

$$
\left(1+\tau_{c}\right)\left[1+\Theta \tau_{c}+\frac{\Theta \tau_{k} r_{t} \widetilde{k}_{t-1}}{(1+\gamma) \widetilde{c}_{t}}+\frac{\Theta \varrho_{t-1} \widetilde{w}_{t}}{\widetilde{c}_{t}}\right]>\left(1-\tau_{w}\right)\left[1+\Theta\left(\frac{1-\mu}{\mu}\right)\left(\frac{1+\tau_{c}}{1-\tau_{w}}\right) \varrho_{t-1}\right]
$$

Ignoring the positive term $\frac{\Theta \tau_{k} r_{t} \widetilde{k}_{t-1}}{(1+\gamma) \widetilde{c}_{t}}+\frac{\Theta \varrho_{t-1} \widetilde{w}_{t}}{\widetilde{c}_{t}}$, if

$$
\left(1+\tau_{c}\right)\left(1+\Theta \tau_{c}\right)>\left(1-\tau_{w}\right)\left[1+\Theta\left(\frac{1-\mu}{\mu}\right)\left(\frac{1+\tau_{c}}{1-\tau_{w}}\right) \varrho_{t-1}\right]
$$

we can be assured that $\Gamma_{t}$ surely is greater than 1 . We will look for sufficient conditions under which the above inequality holds.

$$
\begin{aligned}
\left(1+\tau_{c}\right)\left(1+\Theta \tau_{c}\right) & >\left(1-\tau_{w}\right)\left[1+\Theta\left(\frac{1-\mu}{\mu}\right)\left(\frac{1+\tau_{c}}{1-\tau_{w}}\right) \varrho_{t-1}\right] \\
& \Rightarrow \tau_{c}+\tau_{w}+\Theta \tau_{c}+\Theta \tau_{c}^{2}>\Theta\left(\frac{1-\mu}{\mu}\right)\left(1+\tau_{c}\right) \varrho_{t-1} .
\end{aligned}
$$

Now if

$$
\mu>0.5
$$

clearly, for

$$
\left[\frac{\tau_{c}+\tau_{w}+\Theta \tau_{c}+\Theta \tau_{c}^{2}}{\Theta\left(1+\tau_{c}\right) \varrho_{t-1}}\right]>1>\left(\frac{1-\mu}{\mu}\right)
$$

to hold true, we need

$$
\tau_{c}+\tau_{w}+\Theta \tau_{c}+\Theta \tau_{c}^{2}>\Theta\left(1+\tau_{c}\right) \varrho_{t-1},
$$

or,

$$
\tau_{c}+\tau_{w}+\Theta \tau_{c}+\Theta \tau_{c}^{2}>\Theta\left(1+\tau_{c}\right)\left[R_{t-1}^{P}(1-s)-1\right] \theta_{G}+\Theta \tau_{w}\left(1+\tau_{c}\right)
$$

The LHS is given by

$$
\tau_{c}(1+\Theta)+\tau_{w}+\Theta \tau_{c}^{2}
$$

and the RHS is given by

$$
\Theta\left(1+\tau_{c}\right)\left[R_{t-1}^{P}(1-s)-1\right] \theta_{G}+\Theta \tau_{w}+\Theta \tau_{w} \tau_{c}
$$


If we assume that

$$
\begin{aligned}
\tau_{c} & >\tau_{w}, \\
\text { and } 0 & <\Theta<1,
\end{aligned}
$$

we get

$$
\tau_{w}+\Theta \tau_{c}^{2}>\Theta \tau_{w}+\Theta \tau_{w} \tau_{c}
$$

Hence now the comparison is between $\tau_{c}(1+\Theta)$ and $\Theta\left(1+\tau_{c}\right)\left[R_{t-1}^{P}(1-s)-1\right] \theta_{G}$. Define

$$
\bar{x}=\left[R_{t-1}^{P}(1-s)-1\right] \theta_{G} .
$$

Clearly

$$
0<\bar{x}<1 .
$$

So, is

$$
\tau_{c}(1+\Theta)>\Theta \bar{x}\left(1+\tau_{c}\right) ?
$$

Or

$$
\tau_{c}+\Theta \tau_{c}>\Theta \bar{x}+\tau_{c} \Theta \bar{x} ?
$$

Clearly, since

$$
\begin{aligned}
0 & <\Theta<1 \\
\text { and } 0 & <\bar{x}<1,
\end{aligned}
$$

as long as

$$
\begin{aligned}
\tau_{c} & >\bar{x}, \\
\mu & >0.5,
\end{aligned}
$$

we get

$$
\tau_{c}(1+\Theta)>\Theta \bar{x}\left(1+\tau_{c}\right)
$$

and if

$$
\tau_{c}>\tau_{w}
$$


we get

$$
\begin{aligned}
{\left[\frac{\tau_{c}+\tau_{w}+\Theta \tau_{c}+\Theta \tau_{c}^{2}}{\Theta\left(1+\tau_{c}\right) \varrho_{t-1}}\right] } & >1 \\
& \Rightarrow \Gamma_{t}>1
\end{aligned}
$$

\section{Proposition (3)}

In equation (27) we saw that

$$
\frac{\partial l_{t+1}^{D}}{\partial R_{t}^{P}}=-\frac{l_{t+1}^{D}\left(\theta-s \theta_{G}\right)}{\alpha\left[(1-\theta)+R_{t}^{P}\left(\theta-s \theta_{G}\right)\right]} .
$$

Hence

$$
\begin{aligned}
\left|\frac{1}{\frac{\partial l_{t+1}^{D}}{\partial R_{t}^{P}}}\right| & =\frac{\alpha\left[(1-\theta)+R_{t}^{P}\left(\theta-s \theta_{G}\right)\right]}{l_{t+1}^{D}\left(\theta-s \theta_{G}\right)} \\
& =\frac{\alpha(1-\theta)}{l_{t+1}^{D}\left(\theta-s \theta_{G}\right)}+R_{t}^{P} .
\end{aligned}
$$

Clearly a higher $s$ or $\theta_{G}$ increases the magnitude of $\frac{\alpha(1-\theta)}{l_{t+1}^{D}\left(\theta-s \theta_{G}\right)}$. This implies $\left|\frac{1}{\frac{\partial l_{t+1}^{D}}{\partial R_{t}^{P}}}\right|$ increases which implies $\left|\frac{\partial l_{t+1}^{D}}{\partial R_{t}^{P}}\right|$ decreases. 


\section{$\begin{array}{ll}7 & \text { Figures }\end{array}$}

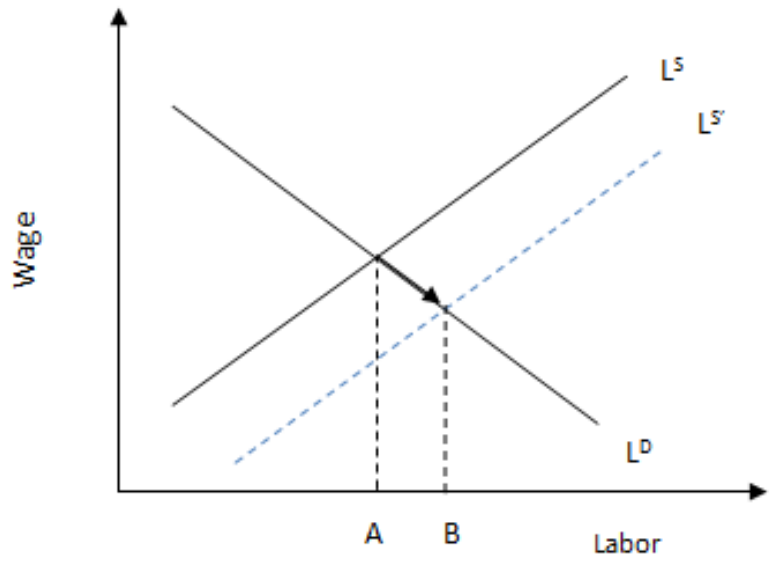

Figure 2: The effect of an increase in $R_{t}^{P}$ on $l_{t}^{S}$

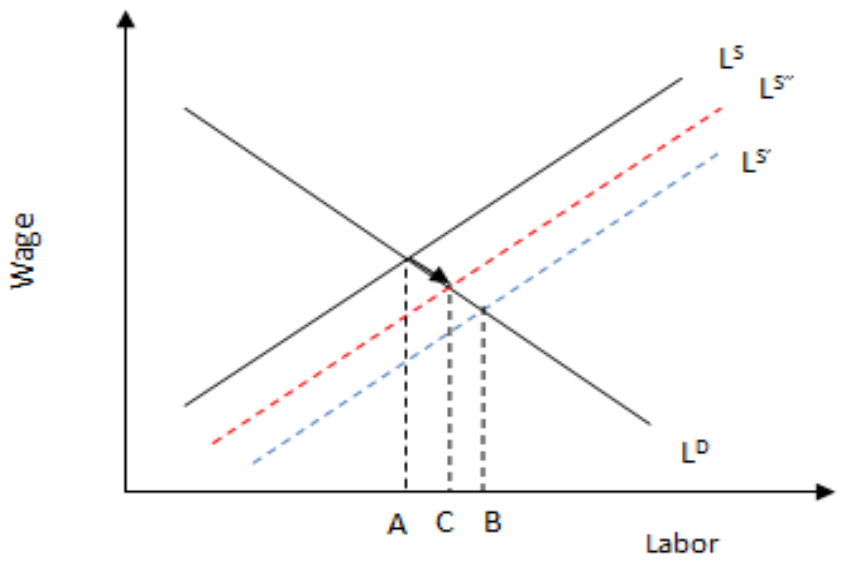

Figure 3: The effect of the wedge $\Gamma_{t}$ on $l_{t}^{S}$ 


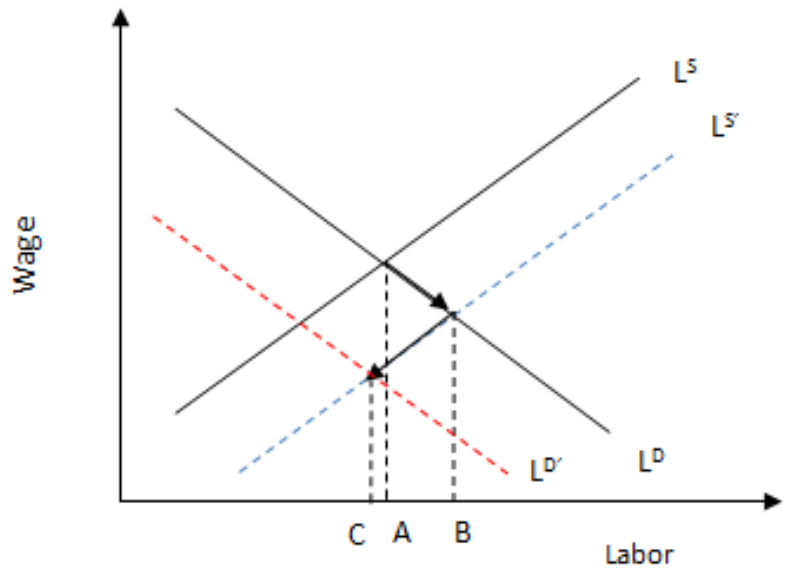

Figure 4: The effect of an increase in $R_{t}^{P}$ on $l_{t+1}^{D}$

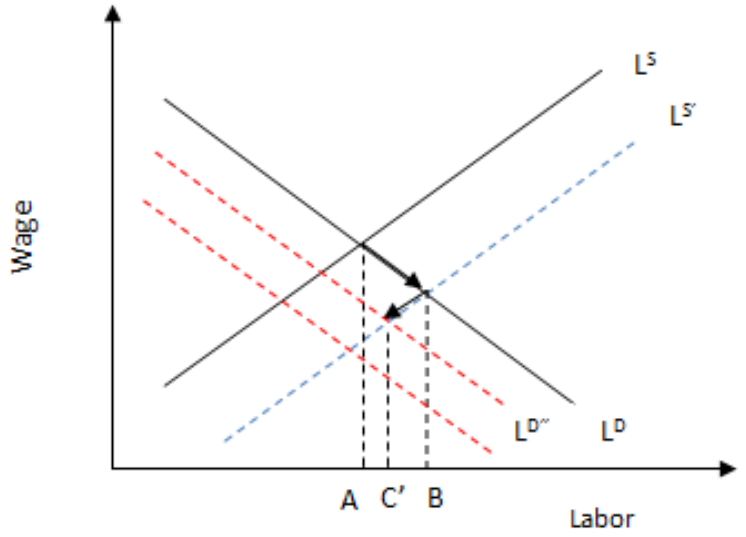

Figure 5: The effect of a subsidy $\theta_{G}$ and $s$ on $l_{t+1}^{D}$ 

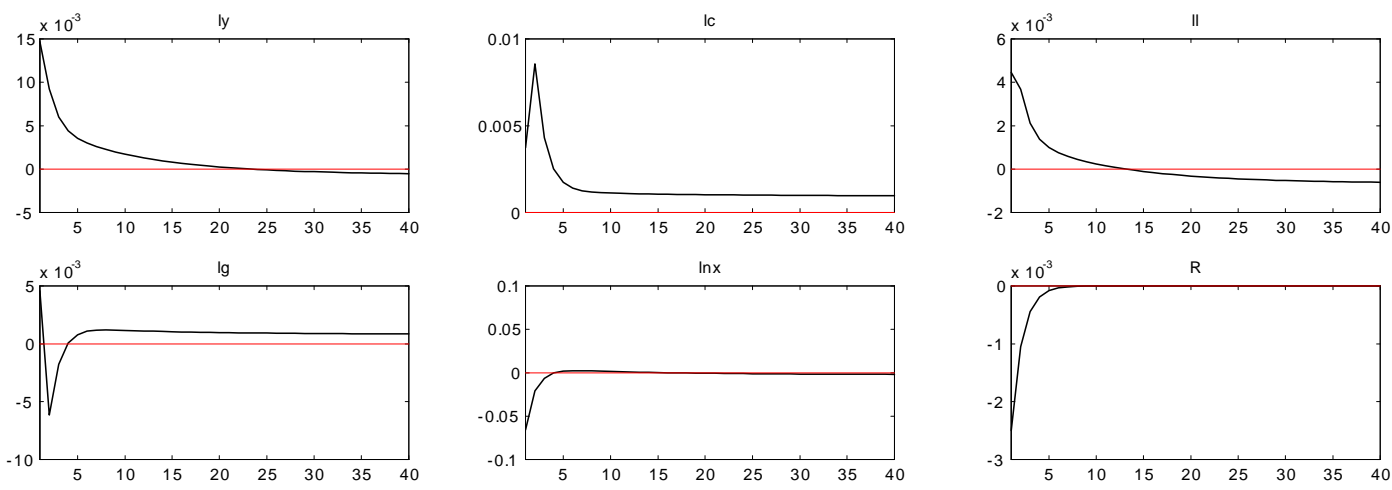

$\ln x$
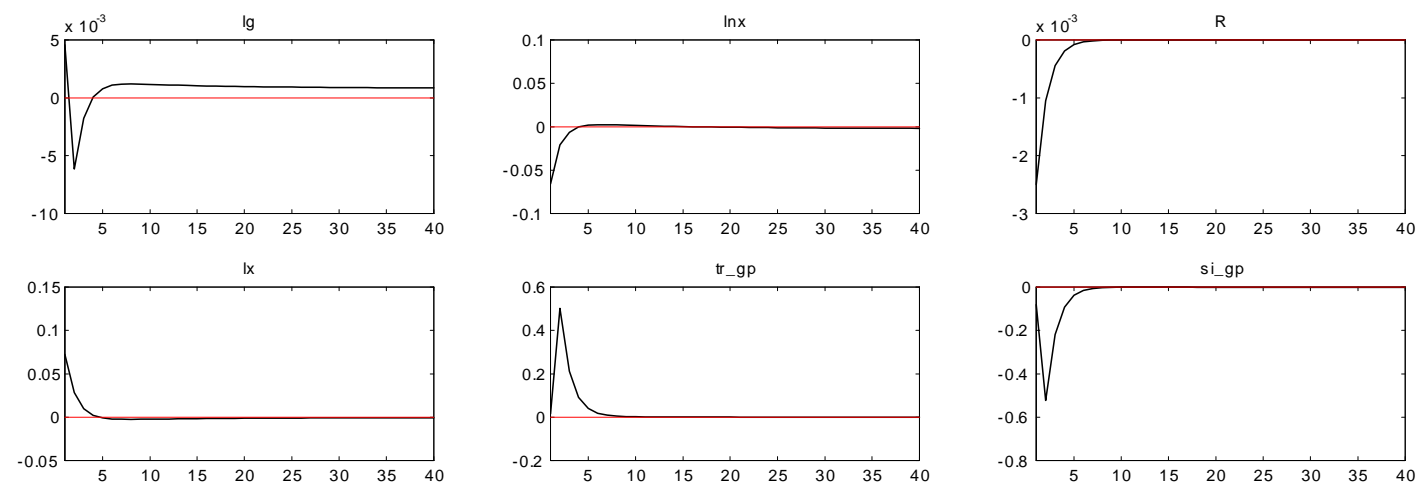

Figure 6: Impact of a single period TFP $(\widehat{A})$ shock
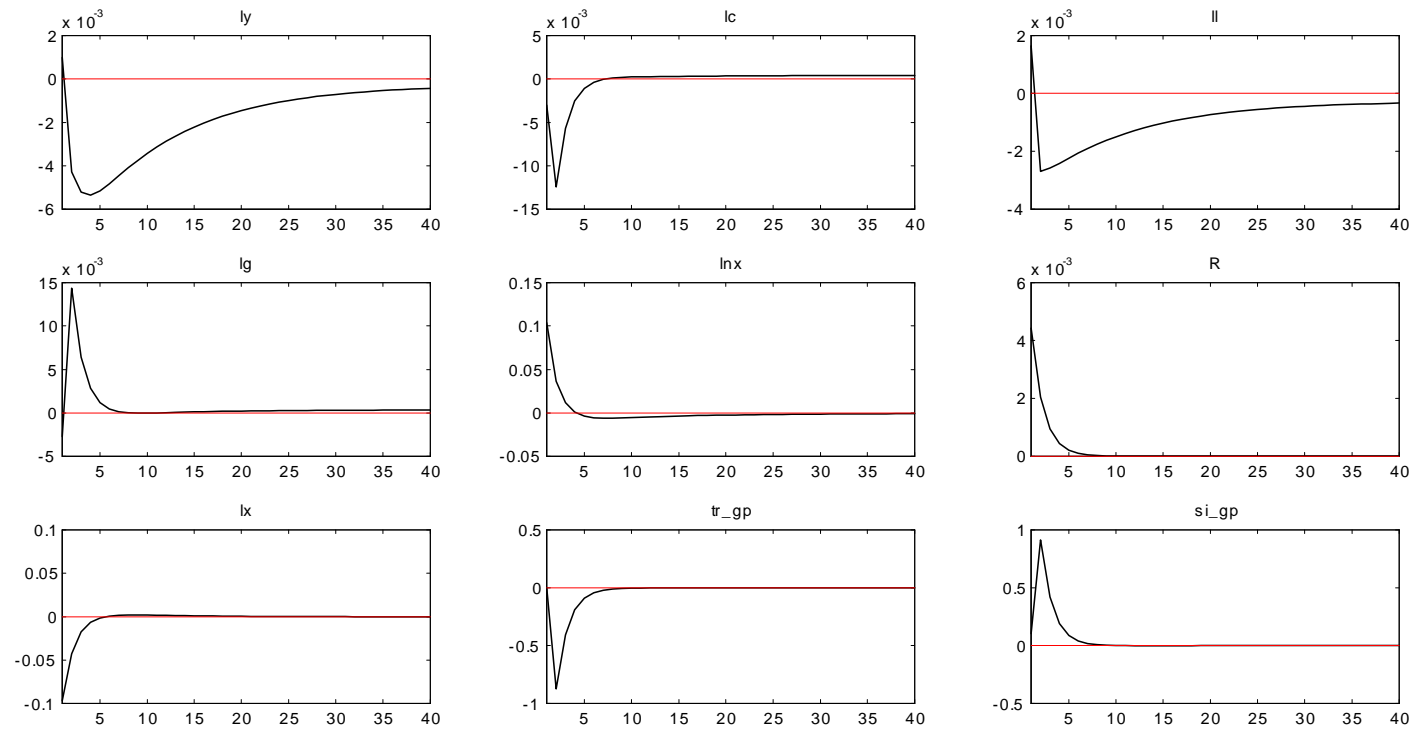

tr_gp

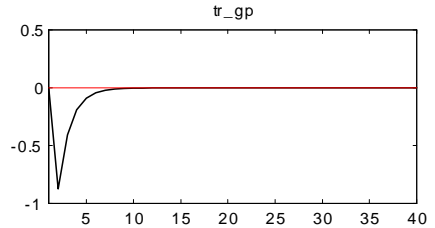

si_gp

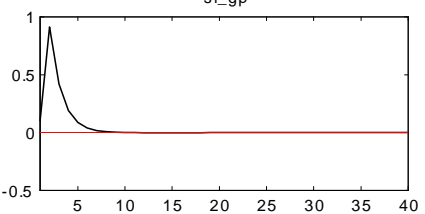

Figure 7: Impact of a single period international interest rate $\left(\widehat{R}^{*}\right)$ shock 

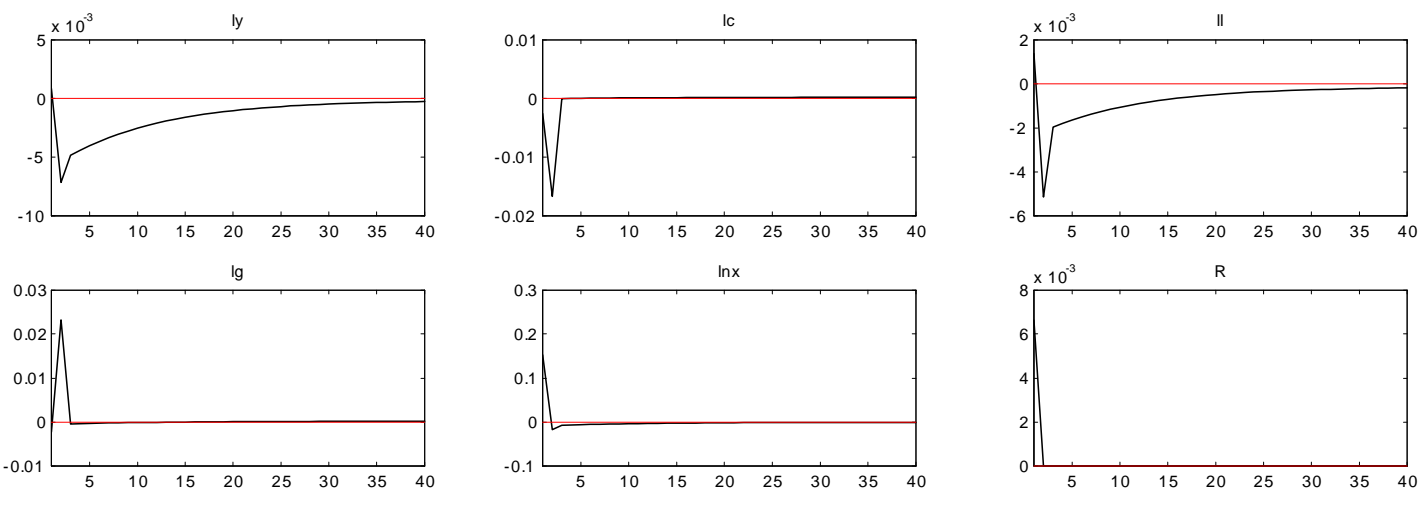

$\ln x$
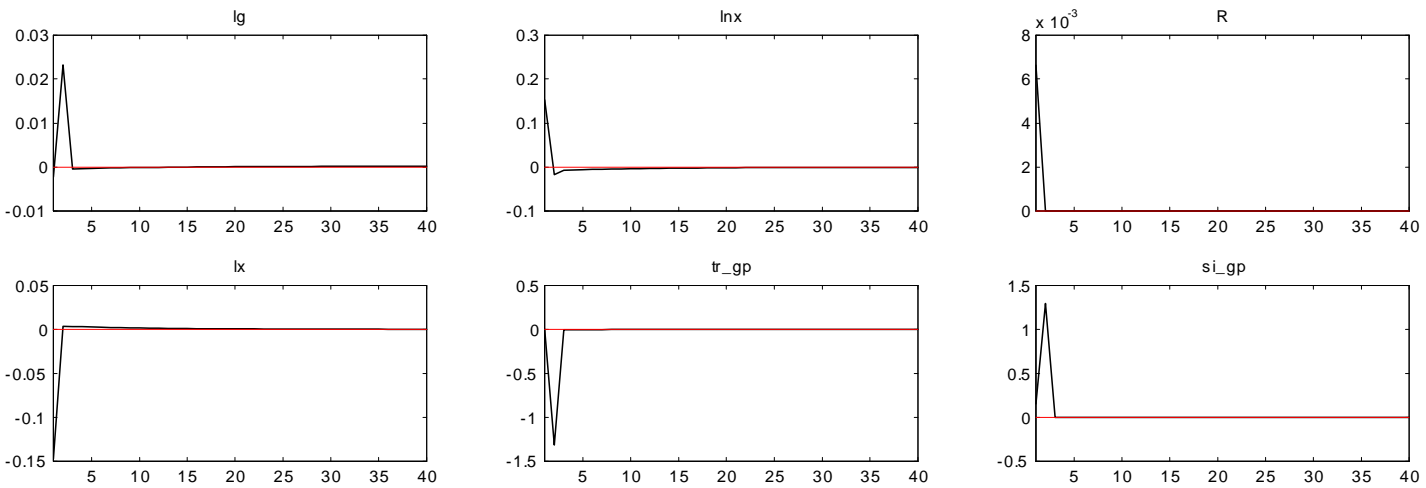

Figure 8: Impact of a single period spread $(\widehat{D})$ shock 